\title{
RESEARCH ARTICLE \\ Tempting goods, self-control fatigue, and time preference in consumer dynamics
}

\author{
Shinsuke Ikeda ${ }^{1}$ (D) Takeshi Ojima ${ }^{2}$
}

Received: 11 March 2018 / Accepted: 7 October 2020 / Published online: 21 October 2020

(c) The Author(s) 2020

\begin{abstract}
We propose a dynamic model of consumer behavior under limited self-control, emphasizing the fatiguing nature of self-regulation. The temptation theory is extended in a two-good setting with tempting and non-tempting goods, where self-regulation in moderating tempting good consumption depreciates mental capital (willpower). The resulting non-homothetic feature of consumer preferences helps describe selfregulatory behavior in such an empirically relevant way that it depends on the nature of the tempting good (luxury or inferior) and on consumer wealth. First, richer consumers are more self-indulgent and impatient in consuming tempting luxuries, whereas less so in consuming tempting inferiors: impatience is marginally increasing in wealth for jewels whereas decreasing for junk foods. Second, self-control fatigue weakens implied patience for tempting good consumption. Third, upon a stressful shock, with the resulting increasing scarcity of willpower, self-indulgence and impatience for tempting good consumption increase over time. Fourth, naive consumers, unaware of the willpower constraint, display weaker self-control in the long run than sophisticated consumers in the same wealth class would do.
\end{abstract}

Keywords Self-control · Willpower · Fatigue · Temptation · Time preference · Luxury

\section{JEL Classification D90 · E21}

\footnotetext{
Many thanks go to Gerhard Sorger and two anonymous referees for critical comments. We are also grateful for helpful discussions to Roy Baumeister, Koichi Futagami, George Loewenstein, Heather M. Maranges, Masao Ogaki, Masahiro Okuno-Fujiwara, Yoshiyasu Ono, Makoto Saito, Ryuzo Sato, Partha Sen, Norio Takeoka, Andy Vonasch, Alexander Wagner, and the participants to the academic meetings at Academia Sinica, Springer Verlag Tokyo, Copenhagen University, Expo Hankyu Hotel, the III MOMA Meeting, Osaka University Nakanoshima Center, and Aoyama Gakuin, Hitotsubashi, Keio and Nagoya Universities. A part of this paper was written when one of us (Ikeda) stayed as visiting scholar at Carnegie Mellon University in 2016 and University of Vienna in 2017. S. Ikeda has received financial support of: the Abe Fellowship from Social Science Research Council; Grants-in-Aid for Scientific Research (B No.17H02499; S No.15H05728; and S No. 20H05631) and for Challenging Research (Exploratory No.18K18576) from the Japan Society for the Promotion of Science; the Joint Usage/ Research Center Project of ISER from the Ministry of Education, Culture, Sports, Science and Technology; Osaka University for its International Joint Research Promotion Program.
}

Extended author information available on the last page of the article 


\section{Introduction}

Consumers are tempted by various kinds of attractive goods, either cheap (e.g., junk food) or extravagant (e.g., jewels). To attain high welfare, they have to regulate themselves not to indulge in consuming tempting goods. However, self-control is stressful and fatiguing (Miller et al. 2015): a self-regulating behavior at a given point in time makes the same behavior more costly thereafter. This would impede consumption smoothing: across goods, e.g., between tempting and non-tempting goods; across time, e.g., before and after a self-regulatory activity; and across states, e.g., across fatigued and unfatigued states. However, economics researchers so far have not discussed how the fatiguing nature of self-control would modify the standard consumer theory based on the permanent income hypothesis. It remains challenging for the existing economic theory to describe actual consumer behavior under temptation and resolve various related issues.

First, many empirical studies report that consumers behave as if they conserve self-control. For example, they become less self-regulatory in consuming tempting goods after an exhausting experience. After the Great East-Japan Earthquake, people in the damaged areas gambled, drank, and overate more (Hanaoka et al. 2018; Ohta 2016). Experimental studies show that an increase in stressful cognitive burdens leads participants to lose self-control in economic decision-making (Shiv and Fedorikhin 1999; Hinson et al. 2003; Vohs and Faber 2007; Fields et al. 2014). People weaken self-control when they have to make intensive self-regulatory efforts in the near future (Muraven et al. 1998; Lempert et al. 2012). All these behaviors seem to be inconsistent with the implicit assumption in the standard economic theory that consumers can exercise self-regulation to attain consumption smoothing without fatigue and at no cost. A deeper understanding of consumer behavior requires incorporating the constraint of limited self-control under which consumers make decisions.

Another unresolved issue relates to the interacting roles played by wealth and selfcontrol in consumers' decision-making. For example, greater wealth holdings enable people to indulge in consuming tempting goods. Indeed, rich people tend to indulge in extravagant tempting goods, such as luxury jewels, high-end brand clothes, etc. (Sombart 1912; Aguiar and Bils 2015), implying that greater wealth reduces the need for self-control. In this sense, wealth plays a role as a substitute for self-control. On the other hand, there is evidence that poor people are more likely to be intemperate towards tempting goods like alcohol, junk food, TV watching, etc. (Banerjee and Duflo 2007; Ubfal 2016): smaller wealth is associated with less self-control. This implies that, in contrast to the case of luxury jewels, poverty and intemperance (therefore wealth and self-control) are complementary with each other.

As self-control relates to patience and hence time preference (Fisher 1930; Thaler and Shefrin 1981), tackling this behavioral issue is important in understanding time preference under temptation. First, it helps explain the empirical fact that time preferences differ between tempting and non-tempting goods (Ashraf et al. 2006; Tsukayama and Duckworth 2010; Reuben et al. 2010; Ubfal 2016). Second, it will enable us to address how consumers' wealth shapes their time preferences for tempting good consumption. If self-control is a substitute for wealth, richer people will exhibit a higher time preference for tempting good consumption, whereas the opposite would 
be true if wealth and self-control are complementary. Describing these relationship would help understand how time preference for tempting goods depends on wealth.

Motivated by these unresolved issues, we aim at developing empirically relevant consumer theory that incorporates intra- and inter-temporal trade-offs due to selfcontrol fatigue under temptation. We propose a model with two unique features. First, by modifying the temptation framework, à la Gul and Pesendorfer (2001, 2004) to a two-good framework, we consider an intertemporal utility maximizer that consumes tempting and non-tempting goods. Tempting good consumption $x$ yields commitment and temptation utility, whereas non-tempting good consumption $c$ generates only commitment utility. Although the consumer is tempted to maximize the temptation utility, his goal is to maximize his total lifetime utility by allocating efficiently his resources intratemporally and intertemporally. Such behavior entails self-control and inflicts mental costs proportional to the gap between maximized and realized levels of temptation utility, which Fudenberg and Levine (2012) refers to as "foregone value." Unlike Gul and Pesendorfer's (2004) one-good model, in which consumers are tempted to allocate all the wealth on present consumption, our two-good model specifies temptation as relating to intratemporal choices, where consumers are tempted to allocate all the permanent income solely on the tempting good consumption.

Second, we incorporate the fatiguing nature of consumers' self-regulation by assuming that self-regulation under temptation entails a limited and depreciable mental capital, which we refer to as willpower. A certain degree of self-regulation to suppress tempting good consumption at a given point in time reduces the willpower resource available for self-regulation thereafter. The consumer has to take into account the resulting intertemporal self-control trade-offs when making decisions. This would shape consumption time-profile and, hence, generate time preferences for the two goods depending on the willpower state even though temptation is specified as enhancing intratemporal preferences for the tempting good.

Due to the good-specific temptation and the state-dependent self-control costs, consumer preferences are generically non-homothetic. We begin by showing that if the intertemporal elasticity of substitution for the tempting good is small enough and/or if that for the non-tempting good is large enough, the tempting good has the nature of luxury, since the expenditure share on it goes up as the consumer gets wealthier; otherwise it is a generically inferior good, whose consumption level becomes lower as he gets richer.

The novelty of our model is that it enables us to describe, in an empirically-relevant way, how consumption dynamics and the associated self-regulating activities depend on the nature of the tempting good (luxury or inferior) as well as on the consumer's wealth level. This will help better understand, from the viewpoint of efficient selfcontrol allocation: $(i)$ distinct consumption behaviors for tempting and non-tempting goods, (ii) the relationship between wealth (or poverty) and self-control (or selfindulgence), (iii) good-specific time preference formation, (iv) the effect of external stressful shocks on consumer behavior, and $(v)$ the behavioral implications of being unaware of the self-control constraint. 
Main results are as follows. First, we show that willpower plays a substitute or complementary role to wealth if the tempting good is a luxury or an inferior good, respectively. When the tempting good $x$ is a luxury, a consumer's willpower to resist the temptation becomes weaker (or stronger) as he accumulates (or decumulates) wealth, whereas when it is an inferior good, he displays stronger (or weaker) willpower when accumulating (or decumulating) wealth. By considering two consumers who differ only in wealth-willpower states, this dynamic characterization can be reinterpreted as characterization in terms of interpersonal comparison: the wealthier consumer is ceteris paribus more self-indulgent in consuming tempting luxury goods, but more self-regulated in consuming tempting inferior ones than the poorer one.

Second, we consider time preferences imputed from tempting and non-tempting consumption behavior and thereby show two implications. First, willpower strengthens patience, measured by time preference, for tempting good consumption, whereas it weakens that for non-tempting good consumption. This implies the occurrence of a domain effect: time preferences differ between tempting and non-tempting goods depending on the willpower state. Second, a wealthier consumer behaves less patiently in consuming a tempting luxury, whereas more patiently in consuming a tempting inferior. This is consistent with the existing empirical finding (e.g., Aguiar and Bils 2015; Ubfal 2016) that the rich tend to indulge more impatiently in consuming tempting luxuries (e.g., entertainments, eating outside), whereas the poor tend to indulge more impatiently in consuming tempting inferiors (e.g., tobacco, starchy plantains). It has been discussed whether time preference is increasing (so called increasing marginal impatience, IMI) or decreasing (decreasing marginal impatience, DMI) in wealth (e.g., Uzawa 1968; Lawrance 1991; Hirose and Ikeda 2012). Our theoretical result implies that it depends on the nature of the domain good: time preference for tempting good consumption exhibits increasing or decreasing marginal impatience as it is a luxury or an inferior good, respectively.

Third, consistent with empirical findings (Fields et al. 2014), upon a permanent stressful shock, a consumer's willpower is weakened due to mental fatigue in steady state. Along with the resulting increasing scarcity of willpower, self-indulgence and impatience for tempting good consumption increase over time.

These results are derived based on the assumption that consumers are sophisticated, in the sense that they are aware of the intertemporal dependence of self-control costs on willpower and incorporate it into their decisions. However, in reality, they will tend to underestimate the self-control capability (Loewenstein 2000, p.60). Incorporating this naivet é of consumers would help describe their regretful behavior that is empirically reported (e.g., Kivetz and Keinan 2006). Thus, we next suspend the assumption of sophisticated consumers by considering the opposite polar case, in which they are completely naive: they are unaware of the presence of the dynamic willpower constraint and change their decisions adaptively to (unconscious) willpower variations over time. Due to the resulting inefficient usage of willpower, naive consumers are shown to have willpower more depleted, and consume more tempting goods in the long run than the sophisticated in the same wealth class.

The remainder of the paper proceeds as follows. Section 2 demonstrates relations of the present study to the literature. Section 3 presents the model and characterizes the optimal solutions. Section 4 discusses the effects of initial values of wealth 
and willpower. Section 5 examines the effects of shifts in the steady-state willpower constraint, such as external stressful shocks. Section 6 considers the case of naive consumers. Section 7 makes comparisons to alternative specifications. Section 8 concludes and discusses on the remaining issues.

\section{Relations to the literature}

\subsection{Self-control, willpower, and mental fatigue}

In social psychology, Roy Baumeister and his joint researchers postulate the "ego depletion" hypothesis for which there exists a mental resource, measured in terms of the blood glucose level, whose depletion, called "ego depletion," causes failure in self-regulation (Baumeister and Vohs 2003), and report many experimental results in support of the hypothesis (Hagger et al. 2010; Baumeister and Vohs 2016a).

Whereas there are controversies in psychology over the partial weakness of their experimental evidence for the ego depletion hypothesis (Baumeister and Vohs 2016b; Hagger 2016), research in other science fields, including brain and medical sciences, provide empirical evidence that self-regulatory efforts cause stress or mental fatigue, with detrimental effects on the quality of decision-makings thereafter. For example, stress studies show that after cognitive and/or non-cognitive tasks requiring selfregulation are experimentally imposed, participants' impatience and impulsivity rise with increased stress hormones secreted, e.g., cortisol (for a meta-analysis, see Fields et al. 2014). Continuous mental burdens cause mental fatigue, giving long-lasting damage to the neuro-system governing the self-regulation capability (Okada et al. 2004; de Lange et al. 2008; Tanaka et al. 2014; Kelley et al. 2015). Self-control efforts in disadvantaged backgrounds lead to greater cardiometabolic risk and faster epidemic aging (Miller et al. 2015; Brody et al. 2016). All these findings imply that self-regulation fatigues mental system, thereby deteriorating the ability for further self-control. Note that fatigue can be mechanically described in models with a stock variable representing a depreciable resource. To capture the fatiguing nature of self-regulation, we thus introduce a depreciable mental capital, the willpower.

Psychology researchers provide the non-resource view of self-control failure: it is postulated that apparent depletion or the "refractory period" takes place in order to trigger a shift in motivation and attention in favor of cheaper behaviors in terms of opportunity costs (Inzlicht and Schmeichel 2012, Inzlicht et al. 2014; Kurzban et al. 2013). In their descriptive theory, however, the determination of mental and opportunity costs of self-regulatory activities and the origination of motivations are an open question. In our model, consumers' behavioral motivations are modeled as induced by their intrinsic objects to maximize utility: they are incentivized to behave so that the marginal utilities, which reflect self-control costs, are equalized intratemporally and intertemporally. Self-regulation dynamics, either moderation or indulgence, are generated jointly with the endogenous determination of motivations (i.e., marginal utilities) and opportunity costs (i.e., marginal utilities of other behaviors) occurring under the willpower constraint. 
We are also concerned with the finding in psychology for which people's self-control capacities are affected when their implicit theories regarding self-regulation ability are manipulated by beliefs of either limited or unlimited self-control resources. Those made to believe the resources are limited show impaired self-regulatory performance (Job et al. 2010, 2015). To reconcile our model to the psychological view of the selfcontrol constraint, we specify self-control costs and the willpower stock in the utility terms, rather than in objective units such as blood glucose assumed by Baumeister in his ego-depletion theory. In our model, willpower availability can thus be affected in a context-dependent way by psychological factors such as "implicit theories," noneconomic motivation, and/or reference self-control levels.

In sum, we abandon the dichotomy between the pure resource view and the pure psychological view, and instead attempt to integrate the competing key factors into an economic model for utility-maximizers. Such a synthetic approach is consistent with recent scientific research on brain and fatigue (Posner and Rothbart 2012; Tanaka et al. 2014; Vohs et al. 2013; Evans et al. 2016), which emphasize the necessity of integrating the resource/biological view and the non-resource/psychological view to describe human behavior under limited self-control.

\subsection{Economic theory of self-control and willpower}

Irrespective of the cumulative studies on self-control depletion in psychology and other fields, there are only a few articles in economics, to our best knowledge, which examine implications of limited self-control capacity for consumers' behavior. Loewenstein (2000) provides deep insights on the theoretical implications of the willpower constraint for decision-making in a descriptive way. He suggests the necessity to understand human behavior from the viewpoint of decisions on efficient willpower allocation. We pursue this approach in this study.

Our research is strongly inspired by Ozdenoren et al. (2012), the first analytical research on consumer behavior under limited willpower. By solving a problem on how a consumer eats a whole cake, they show that time preference for the tempting good (cake) consumption depends negatively on willpower and differ from that for non-tempting good consumption (doing troublesome work). However, as they limit their attention to the specific cake-eating problem, they do not consider the intratemporal choice between tempting and non-tempting goods or the consumption/saving decisions. Moreover, as they assume that period utility for tempting good consumption is satiable, the temptation consumption level there is constant over time. ${ }^{1}$ By developing a more comprehensive model with saving decision and endogenous temptation consumption level, we describe in an empirically consistent way how dynamic consumer behavior and the implied time preference depend on the nature of tempting goods (luxury or inferior) and the wealth of the consumer.

To describe intertemporally dependent self-control behaviors, Fudenberg and Levine (2012) emphasizes the importance of introducing willpower capital to incorporate the convexity property into self-control costs, as we shall do here. By applying Ozdenoren et al.'s willpower model to the dual-self framework, they show that people's

\footnotetext{
1 We will discuss the implication of this assumption in details in Sect. 7.1.
} 
decisions on self-control and commitment depend crucially on the timing structure of temptation and decision making under the convexity property of self-control costs. However, the discussions are limited to one- or two-shot decision problems on whether to accept or reject temptations. In contrast our interest is in implications of limited willpower for continuous consumption/saving decisions and imputed time preferences.

Loewenstein et al. (2015) develops a dual process model for human behavior in which deliberative and affective processes interactively determine human behavior under limited willpower. Although they show several testable predictions including those for intertemporal choice, the discussions are limited to expositions based on illustrative models with exogenous willpower state. Consumers' decision-making in our model has a similar dual structure: one is temptation utility maximization, which could be regarded as an affective process, and the other is total utility maximization, which could be taken as a deliberative process. By endogenizing interactive willpowerself-control dynamics into the model, we shall characterize consumer behaviors by examining analytical solutions. ${ }^{2}$

In contrast to Gul and Pesendorfer (2004), in which the tempted self is assumed to care about today's consumption only, ${ }^{3}$ Noor (2007), Fudenberg and Levine (2012), and Kopylov and Noor (2018) stress the necessity to suppose that the tempted self is forward-looking and maximizes a discounted sum of temptation utility stream. Our approach is in line with theirs: we specify consumers' lifetime utility as the discounted sum of net felicity flow defined as the commitment felicity minus self-control costs. However, unlike their models, in which the tempted (or affective) self is assumed to be less patient than the planning (or deliberative) self, thereby deriving time-inconsistent declining impatience, we assume that the affective self is as patient as the deliberative self in that temptation utility and total utility are equally discounted with the same discount rate as the interest rate.

We adopt this modelling strategy for two reasons. First, our interest is to describe domain effects on time preferences for tempting and non-tempting goods, without assuming a priori a higher discount rate for the tempting good. Given our modelling, domain effects on time preferences are endogenously generated from utility maximizing behavior under limited willpower. Second, in models of time-inconsistent preferences, unique optimum solutions, if any, are usually obtained as time-consistent Markov perfect solutions of intrapersonal games. The resulting time preferences are thus equalized among different time horizons (Krusell et al. 2002) and different goods (Hori and Futagami 2019) as in the usual exponential discounting model with homothetic preferences. Thus, even when assuming a priori a higher discount rate for tempting good consumption and solving the resulting time-inconsistent model, it would be difficult to describe domain effects on time preferences implied from unique optimum consumption paths. Avoiding such theoretical difficulty, we explain domain effects by introducing willpower-dependent self-control costs and the resulting nonhomotheticity into a time-consistent preference model.

\footnotetext{
2 As in the previous studies (Ozdenoren et al. 2012; Fudenberg and Levine 2012; Loewenstein et al. 2015), our model is not based on axiomatic foundation. See also Sect. 8 for related discussions.

3 We discuss how adopting this specification changes our solutions in Sect. 7.3.
} 
By applying Gul and Pesendorfer's temptation model to the Ramsey-type general equilibrium framework, Drugeon and Wlgnlolle (2017) shows that the steady-state wealth distribution depends crucially on the distribution of individual consumers' self-control unit costs and subjective discount rates, where both parameters are exogenously given. Although we do not analyze wealth distribution among heterogeneous consumers, our decision-making model provides a richer framework to discuss wealth holding under limited self-control, where optimal wealth holding, as capital resource for the consumption stream, is jointly determined with willpower, as capital resource for the self-control stream. The resulting steady-state wealth holding is shown to depend on parameters that shape the willpower constraint.

\subsection{Endogenous time preference theory}

Our model has an important implication for a long discussion on whether consumers' time preference is increasing in their wealth (increasing marginal impatience: IMI) or decreasing (decreasing marginal impatience: DMI) (e.g., Uzawa 1968; Epstein 1987; Lawrance 1991; Das 2003; Hirose and Ikeda 2012). We show that good-specific time preferences can be of either type, depending on the type of the good (tempting or not, luxury or inferior). Under weak conditions, consumer behavior is shown to imply IMI for a tempting luxury good, whereas DMI for a tempting inferior good. In the previous literature on endogenous time preferences, IMI or DMI is assumed to be exogenously given. Our model provides a micro-foundation to the shape of the time-preference schedule.

\section{Tempted consumers with limited self-control}

\subsection{The model with tempting and non-tempting goods}

Consider a consumer who lives in infinite time $[0, \infty)$. There are two distinct consumption goods: a tempting good, $x$, and a non-tempting good, $c$. Good $x$ is tempting in the sense that, as discussed more explicitly later, the consumer is tempted to consume a greater amount than he would once he can commit to maximizing long-run welfare. Thus, he has to exercise self-control to restrain himself from consuming too much. In contrast, good $c$ is not tempting: the choice to consume a small quantity of the good does not require any self-control effort.

Taking non-tempting good $c$ as numeraire, let $q$ denote the price of the tempting good $x$, assumed to be constant. Let $a$ be the consumer's financial wealth. He is endowed with constant income $y$ at each point in time. At the constant interest rate $r$, his flow budget constraint at time $t(t \in[0, \infty))$ is given by

$$
\dot{a}_{t}=r a_{t}+y-q x_{t}-c_{t},
$$

where $a_{0}=$ given; the overdot represents the time derivative, that is, $\dot{a}_{t}=d a_{t} / d t$; and the initial financial asset stock $a_{0}$ is exogenously given. 
Let $u(x)$ and $v(c)$ denote the commitment felicity from consumption $x$ and $c$, respectively. Both functions are assumed to be twice continuously differentiable, strictly increasing, and strictly concave. As good $x$ is tempting, the consumer has to make self-control efforts to attain higher long-run welfare. The associated selfcontrol costs in each instant are specified as the product of required self-control efforts $\sigma_{t}$, and the utility costs per self-control effort $\gamma_{t}: \sigma_{t} \gamma_{t}$. To focus on the effect of limited self-control, assume that the self-control effort $\cos t \gamma$ is a decreasing and convex function of the stock of a mental resource $W$ that enables self-control effort: $\gamma=\gamma(W), \gamma^{\prime}(W)<0, \gamma^{\prime \prime}(W)>0$. We refer to this mental resource as willpower. In this setting, the lifetime utility $U_{t}$ is specified as the discounted sum of net felicity flows, that is, the commitment felicity minus self-control effort costs, $u\left(x_{s}\right)+v\left(c_{s}\right)-\gamma\left(W_{s}\right) \sigma_{s}$. In doing so, we follow Ozdenoren et al. (2012) in assuming that the subjective discount rate equals the interest rate $r$. Then, the lifetime utility is given by

$$
U_{t}=\int_{t}^{\infty}\left\{u\left(x_{s}\right)+v\left(c_{s}\right)-\gamma\left(W_{s}\right) \sigma_{s}\right\} \exp (-r(s-t)) d s .
$$

To describe the tempting nature of good $x$ consumption and thereby specify self-control efforts in the simplest manner, assume that the consumer is tempted to maximize his temptation utility $\int_{t}^{\infty} u\left(x_{s}\right) \exp (-r(s-t)) d s$ from good $x$ consumption under the budget constraint (1) and the Non-Ponzi game condition (NPGC hereafter), where the temptation felicity function is assumed to be the same as the commitment felicity function $u .{ }^{4}$ Define the associated indirect temptation utility as

$$
V\left(a_{t}\right)=\max _{\left\{x_{s}\right\}_{s=t}^{\infty} \text { s.t. }(1) \text { and NPGC }} \int_{t}^{\infty} u\left(x_{s}\right) \exp (-r(s-t)) d s .
$$

Since the subjective discount rate is assumed to equal the interest rate $r$ as for the commitment utility, the solution to the right-hand side of Eq. (3) is the flat time-profile $x_{s}=x_{t}^{T}$ for $s \in[t, \infty]$, where

$$
x_{t}^{T}=\frac{r a_{t}+y}{q} \text {. }
$$

We refer to $x_{t}^{T}$ as the temptation consumption level. With $x_{s}=x_{t}^{T}$ for $s \in[t, \infty)$, the indirect temptation utility function is given by

$$
V\left(a_{t}\right)=\frac{1}{r} u\left(\frac{r a_{t}+y}{q}\right)
$$

\footnotetext{
4 Thus, we are assuming that the tempted consumer does not care about good $c$ consumption. Alternatively we could assume that he is tempted tp maximize the temptation utility under Eq. (1) and $c \geq \underline{c}$, where $\underline{c}$ is a constant subsistence level. However, this specification does not affect our model and the related results, except that the temptation consumption level $x_{t}^{T}$, given by Eq. (4), depends on the disposable wealth $a_{t}-$ $\underline{c} / r$, rather than $a_{t}$ only.
} 
To consider the required self-control efforts $\sigma_{t}$ for the consumer at time $t$, imagine a tempted self or the affective system (Loewenstein et al. 2015) inside him who aims to maximize his own affective satisfaction (3). Although the most desirable behavior for the tempted self is to consume the amount $x_{t}^{T}$ in each instant $s \in[t, \infty)$ with no saving, the consumer as the deliberate system actually behaves differently, i.e., consumes $x_{t}$ $\left(\neq x_{t}^{T}\right.$ ) and saves possibly non-zero $\dot{a}_{t}$. The resulting felicity loss for the tempted self, which Fudenberg and Levine (2012) calls foregone value, is the required self-control effort. Formally, this is the difference between $(i)$ the optimal felicity level that would be attained with the most tempting behavior, $u\left(x_{t}^{T}\right)$, and (ii) the suboptimal felicity level that the tempted self obtains when his time- $t$ consumption and saving deviate from $x_{t}^{T}$ and 0 to, respectively, the actual amounts $x_{t}$ and $\dot{a}_{t}, u\left(x_{t}\right)+V^{\prime}\left(a_{t}\right) \dot{a}_{t}{ }^{5}$ As $V^{\prime}\left(a_{t}\right)=u^{\prime}\left(x_{t}^{T}\right) / q$ from Eq. (5), the required self-control effort at time $t$ is given by

$$
\sigma_{t}=u\left(x_{t}^{T}\right)-\left\{u\left(x_{t}\right)+\left(u^{\prime}\left(x_{t}^{T}\right) / q\right) \dot{a}_{t}\right\}
$$

which can be shown to be strictly positive. ${ }^{6}$

The first two terms on the right-hand side represent self-control necessity due to the difference between the temptation and actual consumption levels. The third term captures the negative effect that actual saving (for $\dot{a}_{t}>0$ ) has on self-control need. It reflects that the tempted self has intertemporal preferences Eq. (3), so that the shadow price of saving is positive for the self: A marginal increase in saving contributes to enhancing the tempted self's intertemporal utility by $V^{\prime}\left(a_{t}\right) \dot{a}_{t}$, and hence reducing the need for self-control $\sigma_{t}$. Irrespective of this term, note that the net effect of an increase in tempting good consumption on $\sigma_{t}$ is definitely negative, because $u^{\prime}\left(x_{t}\right)+\left(u^{\prime}\left(x_{t}^{T}\right) / q\right) d \dot{a}_{t} / d x_{t}=u^{\prime}\left(x_{t}\right)-u^{\prime}\left(x_{t}^{T}\right)>0$ (note: $x_{t}<x_{t}^{T}$ ).

\footnotetext{
${ }^{5}$ Generally, the time- $t$ felicity from the temptation consumption flow also equals $u\left(x_{t}^{T}\right)+V^{\prime} \dot{a}_{t}^{T}$, where $a_{t}^{T}$ denotes wealth holdings along the temptation consumption plan. However, $\dot{a}_{t}^{T}=0$ holds along the optimal temptation consumption path. It follows that the time- $t$ felicity from the temptation consumption flow is $u\left(x_{t}^{T}\right)$.

${ }^{6}$ Substituting Eq. (1) into Eq. (6) yields
}

$$
\begin{aligned}
& u\left(x_{t}^{T}\right)-\left\{u\left(x_{t}\right)+\left(u^{\prime}\left(x_{t}^{T}\right) / q\right)\left(r a_{t}+y-q x_{t}-c_{t}\right)\right\} \\
& \geq u\left(x_{t}^{T}\right)-\left\{u\left(x_{t}\right)+\left(u^{\prime}\left(x_{t}^{T}\right) / q\right)\left(r a_{t}+y-q x_{t}\right)\right\} \\
& =u\left(x_{t}^{T}\right)-\left\{u\left(x_{t}\right)+u^{\prime}\left(x_{t}^{T}\right)\left(x_{t}^{T}-x_{t}\right)\right\} \\
& =\left(x_{t}^{T}-x_{t}\right)\left\{\frac{u\left(x_{t}^{T}\right)-u\left(x_{t}\right)}{x_{t}^{T}-x_{t}}-u^{\prime}\left(x_{t}^{T}\right)\right\}>0,
\end{aligned}
$$

where the last inequality follows from the strict concavity of $u$. 
The relevancy of this specification for self-control effort flows can be checked by computing the discounted sum of the $\sigma$ stream Eq. (6) by partial integration to obtain

$$
\int_{t}^{\infty} \sigma_{s} \exp (-r(s-t)) d s=V\left(a_{t}\right)-\int_{t}^{\infty} u\left(x_{s}\right) \exp (-r(s-t)) d s,
$$

which means that, as in Gul and Pesendorfer (2004) and Fudenberg and Levine 2012, the discounted sum of the required self-control effort flows equals the maximized temptation utility minus realized temptation utility. ${ }^{7}$

In sum, in contrast to the usual temptation model with one good ( $\mathrm{Gul}$ and Pesendorfer 2004; Fudenberg and Levine 2012), in which temptation is defined as related to the time allocation of consumption, our two-good model specifies temptation as relating to intratemporal choices, where consumers are tempted to allocate all the permanent income solely on the tempting good consumption.

Willpower dynamics are generated by two factors. First, the consumer is endowed with a constant willpower recovery $\psi$ at each point in time. Second, self-control effort $\gamma_{t} \sigma_{t}$ depletes the mental resource and, hence, decreases the willpower stock available in the next instant. Formally, starting from an exogenously given initial stock $W_{0}$, willpower evolves according to

$$
\dot{W}_{t}=\psi-\alpha \gamma_{t} \sigma_{t},
$$

where $W_{0}=$ given; and $\alpha(>0)$ denotes the strength of the willpower-exhausting effect of self-control efforts.

After substituting Eq. (6) into Eqs. (2) and (8), we summarize the consumer's problem as follows:

Problem (P): Choose the time profile $\left\{c_{t}, x_{t}, a_{t}, W_{t}\right\}_{t=0}^{\infty}$ that maximizes $U_{0}$ :

$$
\int_{0}^{\infty}\left[u\left(x_{t}\right)+v\left(c_{t}\right)-\gamma\left(W_{t}\right)\left\{u\left(x_{t}^{T}\right)-u\left(x_{t}\right)-u^{\prime}\left(x_{t}^{T}\right) \frac{\dot{a}_{t}}{q}\right\}\right] e^{-r t} d t,
$$

subject to Eq. (1), the initial conditions for $\left(a_{0}, W_{0}\right)$, the NPGC, and

$$
\dot{W}_{t}=\psi-\alpha \gamma\left(W_{t}\right)\left\{u\left(x_{t}^{T}\right)-u\left(x_{t}\right)-u^{\prime}\left(x_{t}^{T}\right) \frac{\dot{a}_{t}}{q}\right\}
$$

\footnotetext{
7 For the derivation of Eq. (7), see "Appendix 1". As seen from Eq. (7), if $\gamma$ were constant, the lifetime utility (2) would reduce to

$$
\int_{t}^{\infty}\left\{u\left(x_{s}\right)+v\left(c_{s}\right)\right\} \exp (-r(s-t)) d s-\gamma\left\{V\left(a_{t}\right)-\int_{t}^{\infty} u\left(x_{s}\right) \exp (-r(s-t)) d s\right\}
$$

which is a typical specification of the intertemporal temptation model discussed by Gul and Pesendorfer (2004). However, we cannot rewrite Eq. (2) in such a simple form, because here self-control cost $\gamma$ is not constant, but varies endogenously over time depending on the willpower fluctuation.
} 


\subsection{Optimal consumer behavior}

Let $\lambda(\geq 0)$ and $\eta(\geq 0)$ denote the current-value shadow prices of willpower increments and saving, respectively. Then, the optimality conditions for problem $(\mathrm{P})$ are obtained by maximizing the value of the following current-valued Hamiltonian function

$$
\begin{aligned}
H_{t}= & u\left(x_{t}\right)+v\left(c_{t}\right) \\
& -\gamma\left(W_{t}\right)\left\{u\left(x_{t}^{T}\right)-u\left(x_{t}\right)-u^{\prime}\left(x_{t}^{T}\right) \frac{r a_{t}+y-q x_{t}-c_{t}}{q}\right\} \\
& +\lambda_{t}\left[\psi-\alpha \gamma\left(W_{t}\right)\left\{u\left(x_{t}^{T}\right)-u\left(x_{t}\right)-u^{\prime}\left(x_{t}^{T}\right) \frac{r a_{t}+y-q x_{t}-c_{t}}{q}\right\}\right] \\
& +\eta_{t}\left(r a_{t}+y-q x_{t}-c_{t}\right),
\end{aligned}
$$

as

$$
\begin{aligned}
& \left\{1+\left(1+\alpha \lambda_{t}\right) \gamma\left(W_{t}\right)\right\} u^{\prime}\left(x_{t}\right)-\left(1+\alpha \lambda_{t}\right) \gamma\left(W_{t}\right) u^{\prime}\left(x_{t}^{T}\right)=q \eta_{t}, \\
& v^{\prime}\left(c_{t}\right)-\frac{\left(1+\alpha \lambda_{t}\right) \gamma\left(W_{t}\right) u^{\prime}\left(x_{t}^{T}\right)}{q}=\eta_{t}, \\
& \dot{\lambda}_{t}-r \lambda_{t}=\left(1+\alpha \lambda_{t}\right) \gamma^{\prime}\left(W_{t}\right) \\
& \quad\left\{u\left(x_{t}^{T}\right)-u\left(x_{t}\right)-\frac{u^{\prime}\left(x_{t}^{T}\right)\left(r a_{t}+y-q x_{t}-c_{t}\right)}{q}\right\}, \\
& \dot{\eta}_{t}=-\frac{r\left(1+\alpha \lambda_{t}\right) \gamma\left(W_{t}\right) u^{\prime \prime}\left(x_{t}^{T}\right)\left(r a_{t}+y-q x_{t}-c_{t}\right)}{q^{2}},
\end{aligned}
$$

together with the NPGC for $a$ and the transversality conditions for $W$.

Equation (12) requires that the marginal utility from the tempting good consumption $x$ (LHS) to equal the shadow price of saving (RHS). The marginal utility of $x$ is composed of the direct marginal commitment utility $\left(u^{\prime}\left(x_{t}\right)\right)$ plus the marginal net benefits of economizing self-control costs $\left(\left(1+\left(1+\alpha \lambda_{t}\right) \gamma\left(W_{t}\right)\right) u^{\prime}\left(x_{t}\right)-\right.$ $\left.\left(1+\alpha \lambda_{t}\right) \gamma\left(W_{t}\right) u^{\prime}\left(x_{t}^{T}\right)\right)$. A similar condition for the non-tempting good consumption $c$ is given by Eq. (13). Because of this, the optimal good $c$ consumption is affected by the temptation consumption level $x^{T}$ and willpower level $W$, even though good $c$ is non-tempting. Combining Eqs. (12) and (13) yields the usual condition,

$$
\frac{\left\{1+\left(1+\alpha \lambda_{t}\right) \gamma\left(W_{t}\right)\right\} u^{\prime}\left(x_{t}\right)}{v^{\prime}\left(c_{t}\right)}=q,
$$

which equates the intratemporal marginal rate of substitution between $x$ and $c$ to their relative prices.

Equation (14) represents the Euler condition for the shadow price of willpower savings $\dot{W}$. By integrating the differential equation forwardly, $\lambda_{t}$ can be solved as 
the discounted sum of the marginal benefit of willpower $-\gamma^{\prime}\left(W_{s}\right) \sigma_{s}$ if the steadystate solution exists. ${ }^{8}$ As the required self-control effort $\sigma_{s}$ is strictly positive (see footnote 6$), \lambda_{t}$ is strictly positive. This means that willpower is not free, so that the willpower constraint is necessarily binding, although we do not incorporate explicitly the corresponding Kuhn-Tucker condition.

From the assumption that the discount rate equals the interest rate, the Euler condition (15) for savings requires their shadow price to increase over time in proportion to the negative of the marginal benefits from saving.

We now discuss the properties of the optimum consumer behavior by linearizing the above dynamic system around a steady-state point. As we assume the equality of the primitive discount rate and the interest rate $r$ in utility function (2), the dynamic system has a zero root, so that the steady-state solution depends on the initial values for the two state valuables, $a_{0}$ and $W_{0}$ (Giavazzi and Wyplosz 1985). In what follows, we fix the initial state to an $\left(a_{0}, W_{0}\right)$ value and discuss linearized dynamics around the corresponding steady state. The sensitivity of the solution to the initial state is discussed in Sect. 4.

\subsubsection{Tempting luxury or tempting inferior}

Let us consider local dynamics around a steady-state solution $\left(x^{*}, c^{*}, a^{*}, W^{*}\right)$, where the steady-state solution is discussed in Sect.3.2.4. By combining the linearized versions of Eqs. (16) and (13) through (15), tempting and non-tempting good consumption can be linked as follows (see "Appendix 2" for the derivation):

$$
\frac{c_{t}-c^{*}}{c^{*}}=-\frac{\theta^{c}}{\theta^{x}}\left(\frac{u^{\prime}\left(x^{T}\right)}{u^{\prime}(x)-u^{\prime}\left(x^{T}\right)}\right) \frac{x_{t}-x^{*}}{x^{*}},
$$

where as in what follows, the coefficients are all evaluated at the steady state; and $\theta^{i}$ $(>0)(i=c, x)$ represent the intertemporal elasticity of substitution (IES) for good $i^{\prime}$ s felicity functions: $\theta^{x}=-\left(x u^{\prime \prime} / u^{\prime}\right)^{-1}$ and $\theta^{c}=-\left(c v^{\prime \prime} / v^{\prime}\right)^{-1}$. By construction, the optimal level of tempting good consumption is always smaller than its temptation level, $x<x^{T}$ hence $u^{\prime}(x)>u^{\prime}\left(x^{T}\right)$. Thus, Eq. (17) implies that $x_{t}$ and $c_{t}$ move in opposite directions over time.

By using Eq. (17), we can relate total consumption expenditures, $E \equiv c+q x$, to $x$ by

$$
E_{t}-E^{*}=\varepsilon q\left(x_{t}-x^{*}\right)
$$

$\overline{8}$ Equation (14) is integrated forwardly as

$\lambda_{t}=\int_{t}^{\infty}-\gamma^{\prime}\left(W_{s}\right) \sigma_{s} \exp \left(-\int_{t}^{s}\left(\alpha \gamma^{\prime}\left(W_{k}\right) \sigma_{k}+r\right) d k\right) d s+\lim _{s \rightarrow \infty} \lambda_{s} \exp \left(-\int_{t}^{s}\left(\alpha \gamma^{\prime}\left(W_{k}\right) \sigma_{k}+r\right) d k\right)$.

If a steady-state solution exists, the second term equals zero. The resulting solution implies that $\lambda$ equals the discounted sum of the marginal benefit of willpower (the first term on the RHS). 
where

$$
\varepsilon=\frac{q\left\{u^{\prime}(x) x-u^{\prime}\left(x^{T}\right) x^{T}\right\}+c u^{\prime}\left(x^{T}\right)\left(\theta^{x}-\theta^{c}\right) / \theta^{x}}{q x\left\{u^{\prime}(x)-u^{\prime}\left(x^{T}\right)\right\}} .
$$

Equation (18) represents the linearized optimum relationship between total consumption expenditures and tempting good consumption, from which $\varepsilon$ equals $(d(q x) / d E)^{-1}$, i.e., the inverse of the marginal propensity to spend on $x$ from total expenditures. We call $\varepsilon$ the marginal expenditures-tempting good consumption ratio. As seen from Eq. (19), $\varepsilon$ can be either positive or negative, reflecting that $x_{t}$ and $c_{t}$ move oppositely (see Eq. (17)).

The sign of $\varepsilon$ decides the nature of each good. When $\varepsilon>0$, an increase in $E_{t}$ necessarily co-occurs with an increase in $x$ and, from Eq. (17), with a decrease in $c$. This means that the consumption share of $x$ rises when the budget expands over time and, hence, that the tempting good $x$ is marginally a luxury good. Examples could be extravagant jewels, high-end brand clothes, etc. We call this case $(\varepsilon>0)$ the tempting luxury case. In contrast, when $\varepsilon<0$, the tempting good consumption $x$ decreases as the budget expands over time, meaning that $x$ is marginally an inferior tempting good, such as junk food, cigars, etc. The case that $\varepsilon<0$ is referred to as the tempting inferior case.

Property 1 Tempting good $x$ is a luxury or an inferior good as the marginal expenditures-tempting good consumption ratio $\varepsilon$ is positive or negative, respectively.

When $\varepsilon=0$, the effect of any over-time change in $q x$ on total spending $E$ is cancelled by the opposite change in $c$ of exactly the same amount, so that $E$ and, hence, wealth holdings $a$ are time-invariant. In what follows, to avoid cumbersome taxonomy and focus on the case with wealth-consumption dynamics, we assume $\varepsilon \neq 0$ unless $\varepsilon=0$ is explicitly considered.

Assumption $1 \varepsilon \neq 0$.

As the denominator of the RHS of Eq. (19) is positive, whether $\varepsilon$ is positive or negative and hence whether the tempting good $x$ is marginally a luxury or an inferior good depend on the signs of the two bracketed terms in the numerator of the RHS. We can easily see that $(i)$ the first bracketed term is positive $\left(u^{\prime}(x) x-u^{\prime}\left(x^{T}\right) x^{T}>0\right)$ if the IES for $x$ meets $\theta^{x}<1$; and that (ii) the second bracketed term is positive if $\theta^{x}>\theta^{c}$.

Example 1 Suppose that the felicity functions $u$ and $v$ are of the CRRA type with $\left(\theta^{c}, \theta^{x}\right)$ being constant. Then, as Fig. 1 illustrates, we have:

$-\varepsilon>0$ ( $x$ is a tempting luxury good) if $\theta^{c}<\theta^{x}<1$.

$-\varepsilon<0$ ( $x$ is a tempting inferior good) if $\theta^{c}>\theta^{x}>1$.

Remark 1 In the case of the standard time-additive utility, luxury consumption is characterized by a higher IES (Browning and Crossley 2000; Ikeda 2006). As seen from the above discussion and Fig. 1, in our time-nonadditive utility model, a higher IES 


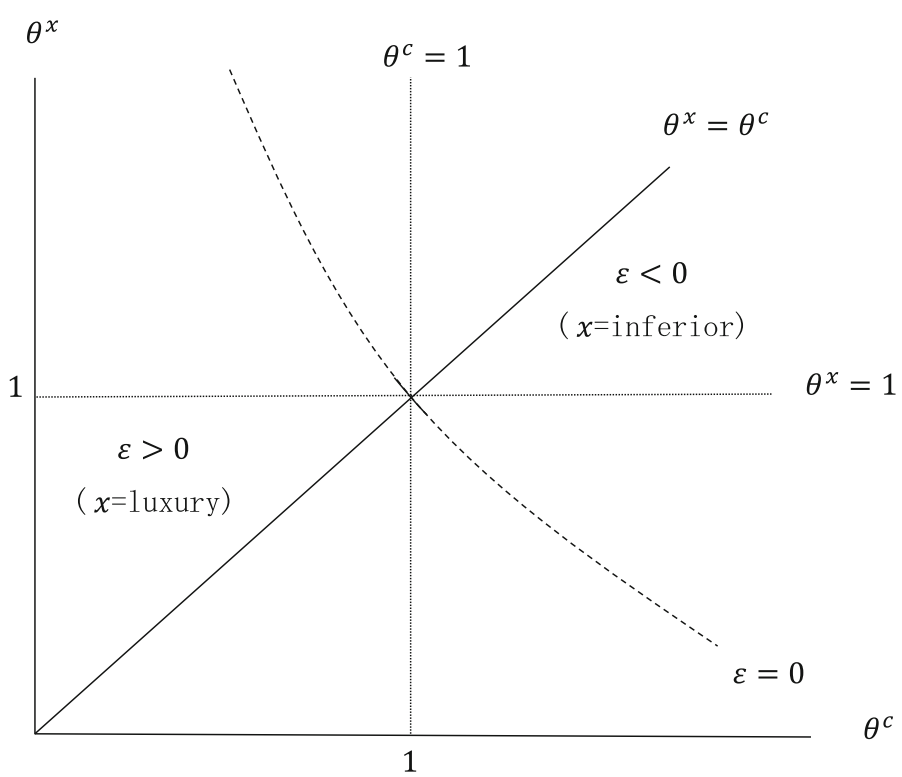

Fig. 1 Intertemporal elasticities of substitution (IES) and the nature of tempting good $x$. Note The figure illustrates the relationship implied by Eq. (19) between the magnitudes of IES for $c$ and $x\left(\theta^{c}, \theta^{x}\right)$ and the signs of $\varepsilon$, i.e., whether $x$ is a luxury $(\varepsilon>0)$ or an inferior $(\varepsilon<0)$. The $\varepsilon=0$ schedule represents the locus of points $\left(\theta^{c}, \theta^{x}\right)$ that satisfy $\varepsilon=0$. The schedule splits the space to the $\varepsilon>0$ region (the west area) and the $\varepsilon<0$ region (the east area). The slope can be shown to be negative in the neighborhood of $\left(\theta^{c}, \theta^{x}\right)=$ $(1,1)$

is not necessary or sufficient for the good to be a luxury: even when $\theta^{x}<\theta^{c}, x$ can be a luxury if $\theta^{x}$ is sufficiently smaller than one, so that $\left(\theta^{c}, \theta^{x}\right)$ lies below the $\varepsilon=0$ schedule in Fig. 1; and even when $\theta^{x}>\theta^{c}, x$ can be an inferior good if $\theta^{x}$ is sufficiently larger than one, so that it is located above the $\varepsilon=0$ schedule in Fig. 1.

\subsubsection{Self-control, consumption, and wealth}

By linearizing the optimality conditions (1), (4), (10), and (12) through (15), the consumer behavior can be described in the reduced three-dimensional system with respect to $\left(x_{t}-x^{*}, W_{t}-W^{*}, a_{t}-a^{*}\right)$. By assuming that the optimum dynamics is stable and unique, ${ }^{9}$ we can show that the optimum time-path of willpower, as a state variable, is given by $\dot{W}_{t}=\chi\left(W_{t}-W^{*}\right)$, where $\chi$ represents a negative characteristic root of the linearized dynamic system. Given the time- $t$ willpower stock $W_{t}$, optimal tempting good consumption $x_{t}$ is determined by the following linearized equation:

$$
x_{t}-x^{*}=\frac{\left\{u^{\prime}(x)-u^{\prime}\left(x^{T}\right)\right\}\left[\chi+\alpha \gamma^{\prime}\left\{u\left(x^{T}\right)-u(x)\right\}\right]}{\alpha \gamma\left[\left\{u^{\prime}(x)-u^{\prime}\left(x^{T}\right)\right\}^{2}+\frac{c}{q x} \frac{\theta^{c}}{\theta^{x}} u^{\prime}\left(x^{T}\right)^{2}\right]}\left(W_{t}-W^{*}\right) .
$$

\footnotetext{
${ }_{9}$ For the stability condition, see Appendix 3, in which we derive the condition and show a sufficient condition for it.
} 


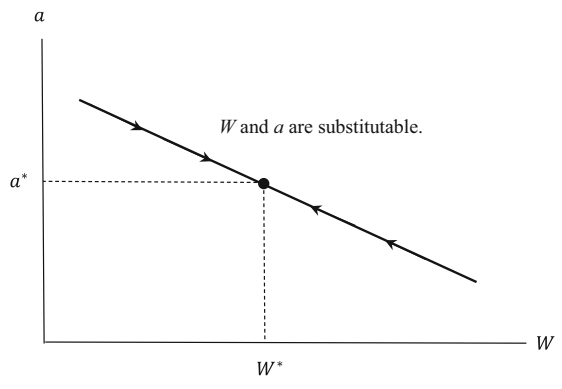

(a) $\varepsilon>0$ : tempting luxury

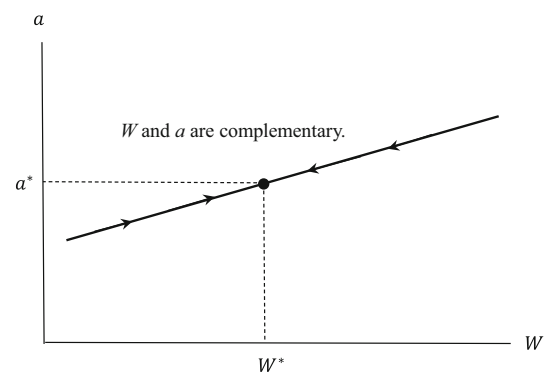

(b) $\varepsilon<0$ : tempting inferior

Fig. 2 Relationship between willpower and wealth as capital resources. Note The schedules represent Eq. (21). In the tempting luxury case $(\varepsilon>0)$, the steady-state point is necessarily located north-west or southeast of the given initial point. In the tempting inferior case $(\varepsilon<0)$, the steady-state point necessarily lies north-east or south-west of the initial point. For the determination of the steady-state point, see Sect. 3.2.4

As the coefficient on the right-hand side of Eq. (20) is negative, the tempting good consumption is negatively associated with the willpower stock. From Eq. (17), this in turn implies that the non-tempting good consumption and the willpower stock are positively associated. This can be summarized as follows.

Property 2 An over-time decrease in willpower is associated with over-time consumption shifting from non-tempting good $c$ in favor of tempting good $x$.

Property 2 shows that when a consumer's willpower depreciates over time, he gradually weakens self-control against temptation from $x$ to conserve the willpower. However, the resulting increase in tempting good consumption may or may not be associated with wealth decumulation. It depends crucially on whether $x$ is a luxury or an inferior good, as we shall show next.

To relate optimal wealth holdings with willpower, set $a_{t}-a^{*}$ as linear in $W_{t}-W^{*}$, and determine its coefficient such that it validates the linearized equation of Eq. (1) under Eq. (20). Then, we can obtain

$$
a_{t}-a^{*}=-\Omega\left(W_{t}-W^{*}\right),
$$

where

$$
\Omega=\frac{q\left\{u^{\prime}(x)-u^{\prime}\left(x^{T}\right)\right\}\left[\chi+\alpha \gamma^{\prime}\left\{u\left(x^{T}\right)-u(x)\right\}\right]}{\alpha \gamma(\chi-r)\left[\left\{u^{\prime}(x)-u^{\prime}\left(x^{T}\right)\right\}^{2}+\frac{c}{q x} \frac{\theta^{c}}{\theta^{x}} u^{\prime}\left(x^{T}\right)^{2}\right]} \varepsilon \geq 0 \Leftrightarrow \varepsilon \geq 0 .
$$

Thus, under Assumption 1, as illustrated in Fig. 2, wealth holdings comove or inversely move with willpower, as the tempting good is a luxury $(\varepsilon>0)$ or an inferior $(\varepsilon<0)$, respectively. ${ }^{10}$

\footnotetext{
$\overline{10}$ When $\varepsilon=0$, Eq. (21) implies that $a_{t}=a^{*}$ : the wealth stays at the initial steady-state value, as explained earlier.
} 
To understand economically this relationship between wealth and willpower, it is helpful to regard them as capital resources to produce utility: wealth is a capital resource for future consumption, whereas willpower for future self-control. Using the terminology in the capital theory (e.g., Jones 2014), we characterize the two capital resources as being substitutable to each other if an accumulation in one reduces the need for the other, whereas complementary if an accumulation of one enhances the need for the other.

Equation (21) and hence Fig. 2 imply that in the tempting luxury case $(\varepsilon>0)$, wealth and willpower are substitutable for each other, whereas in the tempting inferior case $(\varepsilon<0)$, they are complementary.

Property 3 In the case of tempting luxury $(\varepsilon>0)$, willpower and wealth are substitutable $(\operatorname{sign}(\dot{W})=-$ sign $(\dot{a}))$, whereas in the tempting inferior case $(\varepsilon<0)$ the two are complementary $(\operatorname{sign}(\dot{W})=\operatorname{sign}(\dot{a}))$.

Intuitively, restraining tempting good consumption induces demand for willpower. When the tempting good is a luxury, a consumer who accumulates wealth indulges more easily in savoring it and, hence, decumulates unnecessary willpower. Conversely, when willpower is under accumulation, he will restrain himself from consuming the tempting luxury good and decumulate unnecessary wealth. Therefore, wealth and willpower play substitutable roles as capital resources. When the tempting good is an inferior good, a consumer who get poorer eats more junk food with less need for willpower. Conversely, willpower accumulation leads to a decrease in $x$ and an increase in $c$ by a greater amount. The resulting increase in total expenditures enhances the need for wealth, thereby leading to greater saving. Thus, the two resources are complementary.

This property helps characterize the consumer behavior toward tempting luxury and inferior goods in terms of the states of wealth and willpower as follows:

Proposition 1 The wealthier a consumer becomes, the less self-regulated he becomes in consuming a tempting luxury good, but more self-regulated in consuming a tempting inferior good.

As in the literature of consumption expenditures (e.g., Blundell and Ray 2084; Attanasio and Pistaferri 2016), we can reinterpret this dynamic characterization of luxury/inferior good consumption in terms of the cross-sectional comparison. Consider two consumers who differ only in the wealth-willpower states, i.e., those who are represented by two distinct points on the same optimum trajectory (21). Then, the richer consumer is ceteris paribus more self-indulgent in luxury (jewels) and more self-regulated in inferior goods (junk food) than the poorer one.

\subsubsection{Time preferences}

From Property 2 and Proposition 1, we can conjecture that time preference and, hence, the degrees of impatience that shape the consumption time-profile would differ 
between tempting and non-tempting good consumption. For formal discussion, we follow the literature (e.g., Epstein 1987; Obstfeld 1990) in defining the pure rate of time preference for good $i(i=x, c), \delta^{i}$, as the negative of the logarithmic time-derivative of the present-value marginal utility of $i$ in the Voltera sense, evaluated at $i=0$. As the present-value marginal utility of good $i$ consumption is expressed in terms of the current-value marginal utility as $\exp (-r t) M U_{i t}$, where the current-value marginal utility $M U_{x t}$ and $M U_{c t}$ represent the LHS of Eqs. (12) and (13), respectively, the time preference rate for each consumption good is given by

$$
\delta_{t}^{x}=r-\left.\left(\ln \dot{M} U_{x t}\right)\right|_{\dot{x}=0}, \delta_{t}^{c}=r-\left.\left(\ln \dot{M} U_{c t}\right)\right|_{\dot{c}=0} .
$$

From the expressions of $M U_{x t}$ and $M U_{c t}$, the time preference rates depend on all the endogenous variables, $c_{t}, x_{t}, a_{t}, W_{t}, \eta_{t}$, and $\lambda_{t}$. Instead of characterizing the time preference functions in terms of partial derivatives with respect to each variable, we follow the literature (e.g., Becker and Mulligan 1997) in focusing on the rates of time preference along the optimum consumption time path. They are the time preferences implied from the optimum consumer behavior. By substituting the optimality conditions into Eq. (22), "Appendix 4" derives the time preference rates as

$$
\begin{aligned}
\delta_{t}^{i} & =r+\Lambda^{i}\left(W_{t}-W^{*}\right), i=x, c ; \\
\Lambda^{x} & =-\frac{r \chi \gamma(1+\alpha \lambda) u^{\prime \prime}\left(x^{T}\right)\left[\chi+\alpha \gamma^{\prime}\left\{u\left(x^{T}\right)-u(x)\right\}\right]}{q \alpha \eta(\chi-r)\left\{u^{\prime}(x)-u^{\prime}\left(x^{T}\right) \varepsilon\right\}}\left(\varepsilon-\varepsilon_{-}\right), \\
\Lambda^{c} & =\frac{r \chi \gamma(1+\alpha \lambda) u^{\prime \prime}\left(x^{T}\right)\left[\chi+\alpha \gamma^{\prime}\left\{u\left(x^{T}\right)-u(x)\right\}\right]}{q \alpha \eta(\chi-r)\left\{u^{\prime}(x)-u^{\prime}\left(x^{T}\right) \varepsilon\right\}}\left(\varepsilon_{+}-\varepsilon\right) .
\end{aligned}
$$

where letting $\theta^{T}\left(=-\left[x^{T} u^{\prime \prime}\left(x^{T}\right) / u^{\prime}\left(x^{T}\right)\right]^{-1}(>0)\right)$ denote the IES for temptation felicity function, $\varepsilon_{-}$and $\varepsilon_{+}$are defined as

$$
\begin{aligned}
& \varepsilon_{-}=-\left(\frac{x^{T}}{x}\right)\left(\frac{1+\gamma(1+\alpha \lambda)}{(1+\alpha \lambda) \gamma}\right)\left(\frac{u^{\prime}(x)}{u^{\prime}\left(x^{T}\right)}\right)\left(\frac{r-\chi}{r}\right)\left(\frac{\theta^{T}}{\theta^{x}}\right), \\
& \varepsilon_{+}=-\left(\frac{u^{\prime}\left(x^{T}\right)}{u^{\prime}(x)-u^{\prime}\left(x^{T}\right)}\right) \varepsilon_{-} .
\end{aligned}
$$

On the right hand sides of these equations, all the parenthesized factors except for $\theta^{T} / \theta^{x}$ are greater than one, so that $\varepsilon_{-}<-\theta^{T} / \theta^{x}$ and $\varepsilon_{+}>\theta^{T} / \theta^{x}$. We also have $\varepsilon \leq 1$. From these properties, we can show that under weak conditions, the marginal expenditures-tempting good consumption ratio $\varepsilon$ satisfies

$$
\varepsilon_{+}>\varepsilon>\varepsilon_{-},
$$

around the steady state, so that we have $\Lambda^{x}<0$ and $\Lambda^{c}>0$. "Appendix 4" derives the sufficient conditions for Eq. (24), which include: 
Example 2 We have:

$-\varepsilon>\varepsilon_{-}$if the consumer is weakly prudent for $x\left(u^{\prime \prime \prime} \geq 0\right)$ and $\theta^{c} \leq 1$;

$-\varepsilon<\varepsilon_{+}$if $\theta^{T} \geq \theta^{x}$, or the IES for $u(x)$ is weakly increasing in $x$,

both of which are simultaneously met, for example, if $u$ is of the CRRA type and $\theta^{c} \leq 1$. $^{11}$

In what follows, we assume inequality (24) to focus on the normal situation:

Assumption 2 The marginal expenditures-tempting good consumption ratio $\varepsilon$ satisfies Eq. (24).

Remark 2 If $\varepsilon<\varepsilon_{-}$, the consumer would paradoxically increase (or decrease) $x_{t}$ over time when the corresponding time preference $\delta_{t}^{x}$ is higher (or lower) than its steadystate value $r$ : he would restrain (or indulge in) $x$ when he is impatient (or patient). This could occur because in that case the marginal return of saving is high (or low) under $W_{t}>W^{*}$ (or $W_{t}<W^{*}$ ), which leads him to restrain (or indulge in) $x$ irrespective of a high (or low) time preference. ${ }^{12}$ Similarly, if $\varepsilon>\varepsilon_{+}, c$ increases (or decreases) over time when $\delta_{t}^{c}>r$ (or $\delta_{t}^{c}<r$ ) as the return of savings becomes dominantly high (or low) under $W_{t}<W^{*}$ (or $W_{t}>W^{*}$ ). However, unlike the normal case that we focus on under Assumption 2, it is difficult to show explicitly the parametric regions in which these paradoxical cases occur.

With Assumption 2, Eq. (23) implies that a greater willpower is associated with a lower rate of time preference for tempting good consumption $\left(\Lambda^{x}<0\right)$. This reflects consumer behavior toward efficient self-regulation. A consumer who is too fatigued mentally to exercise self-control required for the long-run optimum allow himself to impatiently shift consumption from non-tempting to tempting goods, and thereby, conserve the self-control resource. In contrast, with willpower exceeding the long-run need, the consumer patiently restrains himself from consuming tempting goods by incurring the self-control costs. We summarize the property of impatience for $x$ as follows:

Property 4 Impatience for tempting good consumption, measured by its optimal time preference, is (i) higher or lower than its steady-state value ( $r$ ), as willpower is currently scarcer or less scarce than it would be in the future steady-state; and (ii) weakened by self-control fatigue.

Theoretically, whether $\delta_{t}^{x}$ is higher or lower than the stead state value depends on two factors: (1) how willpower affects the marginal utility of the consumption; and (2) whether the current scarcity of willpower, measured by the shadow price, is higher

\footnotetext{
11 As seen from Fig. 1, $x$ can be either luxury or inferior even when $\theta^{c} \leq 1$.

${ }^{12}$ Formally, note that the Euler condition is written in terms of time preference $\delta^{x}$ as
}

$$
\dot{x}_{t}=-\left(M U_{x}^{x} / M U_{x x}^{x}\right)\left(H_{a t}-\delta_{t}^{x}\right),
$$

where the marginal return of saving is given by $H_{a}$, i.e., the first derivative of the current-value Hamiltonian by $a$. The derivative $H_{a}$ equals the negative of the RHS of Eq. (15). We can show that $H_{a}$ positively depends on $W-W^{*}$ when $\varepsilon<\varepsilon_{-}$, whereas it negatively depends on $W-W^{*}$ when $\varepsilon>\varepsilon_{+}$. 
or lower than the future steady-state value. Ozdenoren et al. (proposition 1, p.355, Ozdenoren et al. 2012) shows that, given a positive shadow price of self-control, time preference for a tempting good (cake) can be either higher or lower than that in the perfect smoothing case (zero in that model), depending on how an increase in willpower affects the marginal utility of eating cake, i.e., factor (1). As willpower in their model is scarce during the finite period under consideration, the shadow price of self-control is definitely higher than or equal to the future value (zero) at the terminal date. Thus, in the Ozdenoren et al. model, factor (2) is fixed by construction, so that time preference for eating cake is determined solely by factor (1). However, as the self-control function is given ad hoc there, they cannot determine how factor (1) works.

In contrast, our model with micro-founded self-control costs can decide how (1) works: an increase in $W_{t}$ definitely increases $x_{t}$ (Eq. (20)), which implies a decrease in the total marginal utility of $x$. On the other hand, the current relative scarcity of self-control (factor (2)) here is determined by whether $W_{t}$ is smaller or greater than $W^{*}$. It follows that, contrasting to Ozdenoren et al.'s result, factor (2) determines whether time preference for $x_{t}$ is higher or lower than the future steady-state value. This is what Property 4 summarizes.

It has been pointed out that time preference depends on the type of the underlying consumption domain (e.g., Frederick et al. 2002). Equation (23) reveals that such a "domain effect" on time preference occurs when the consumer preferences for individual goods depend on their degrees of temptingness and the consumer's willpower state. $^{13}$

This domain-dependent nature of time preferences has an interesting implication if we relate $\delta^{i}$ to wealth holdings. Substituting Eq. (21) into (23) yields

$$
\delta_{t}^{i}=r-\frac{\Lambda^{i}}{\Omega}\left(a_{t}-a^{*}\right), i=x, c .
$$

Recall that $\Omega$ has the same sign as $\varepsilon$. Thus, coefficient $-\Lambda^{i} / \Omega$ has the same sign as $\varepsilon$ for $i=x$ and an opposite sign to $\varepsilon$ for $i=c$. In the literature (e.g., Epstein 1987; Obstfeld 1990), time preference is said to exhibit increasing marginal impatience (IMI) or decreasing marginal impatience (DMI), as it increases or decreases in wealth holdings. With Assumption 2, Eq. (25) implies that time preference for tempting good $x$ exhibits IMI or DMI depending on whether $x$ is a luxury or an inferior good, as summarized below.

Proposition 2 The wealthier a consumer becomes, the less patient he is in consuming a tempting luxury, whereas the more patient he is in consuming a tempting inferior good. That is, consumer behavior exhibits IMI for a tempting luxury good but DMI for a tempting inferior good.

From the discussion below Proposition 1, we can reinterpret Proposition 2 as characterizing tempting luxury/inferior goods in terms of rich-poor difference in the good-specific time preference: for tempting luxuries, rich people are less patient than

\footnotetext{
13 See Ikeda (2006), which shows a domain effect on time preference that occurs between luxury and necessity goods.
} 
the poor, whereas for tempting inferiors the opposite is true. This rich-poor contrast in time preference is consistent with what several empirical studies report (Sombart 1912; Banerjee and Duflo 2007; Aguiar and Bils 2015; Ubfal 2016). For example, Aguiar and Bils (2015) shows that, associated with income growth during 1980-2010, rich people became indulgent for tempting luxury, e.g., entertainment, more rapidly than the poor, whereas the poor's indulgence for inferior tempting goods, e.g., tobacco, was enhanced more rapidly (or weakened more slowly) than the rich's. By using survey data of poor people in Uganda, Ubfal (2016) estimates good-specific time preferences, thereby showing that the poor participants display high time preference for inferior or necessary tempting goods like starchy plantains, whereas they exhibit low time preference for luxury temptations, e.g., entertainments, eating outside. Although these empirical studies did not measure rigorously the tempting nature of the goods, their findings could be summarized as that richer consumers tend to indulge more in consuming tempting luxuries impatiently, whereas they are likely to be more impatient for inferior goods.

Proposition 2 describes this empirical tendency by referring to the nature of tempting goods. Consuming a tempting luxury (e.g., entertainment in Aguiar and Bils 2015; and Ubfal 2016) needs greater wealth and less willpower. Thus, when people are rich, they choose to consume more tempting luxury with less self-control and, hence, revealing higher time preference than they would when they are poor, i.e., the IMI is the case. In contrast, when the tempting good is an inferior good (e.g., tobacco in Aguiar and Bils 2015), consuming it is associated with small wealth and weak willpower. So when people are rich, they moderate tempting good consumption using stronger willpower and, hence, with lower time preference than they would when poor, i.e., the DMI follows.

Two points are theoretically noteworthy. First, in previous theoretical studies on endogenous time preference, IMI or DMI is exogenously specified. Proposition 2 shows that a good-specific time preference can be of either type, depending whether the domain good is tempting or not, and whether it is a luxury or an inferior good. In this sense, this model provides a micro-foundation to the shape of time preference.

Second, from Eq. (25) for the non-tempting good consumption $c$, the time preference for $c$ is of the DMI type when it is an inferior whereas it is of the IMI type when it is a luxury. Combining this with Proposition 2 yields the following corollary:

Corollary 1 Time preference is of the IMI type for luxury good consumption, whereas it is of the DMI type for inferior good consumption.

This is a natural consequence of the definitions of luxury and inferior goods, because the consumption propensities are increasing in wealth (permanent income) for luxury goods and decreasing for inferior goods.

\subsubsection{Steady-state solution}

The steady-state solution $\left(x^{*}, c^{*}, a^{*}, W^{*}, \lambda^{*}, \eta^{*}\right)$ is obtained by setting $(\dot{W}, \dot{a}, \dot{\lambda})=0$ in differential equations (1), (10), and (14), and combining the results with Eqs. (4), (13), (16), and (21), where Eq. (21) is evaluated at the initial point in time. Explicitly, 
it is determined by the following six equations:

$$
\begin{aligned}
& \alpha \gamma\left(W^{*}\right)\left\{u\left(\frac{r a^{*}+y}{q}\right)-u\left(x^{*}\right)\right\}=\psi, \\
& r a^{*}+y=q x^{*}+c^{*}, \\
& \frac{\left\{1+\left(1+\alpha \lambda^{*}\right) \gamma\left(W^{*}\right)\right\} u^{\prime}\left(x^{*}\right)}{v^{\prime}\left(c^{*}\right)}=q, \\
& \lambda^{*}=-\frac{\gamma^{\prime}\left(W^{*}\right)\left\{u\left(\frac{r a^{*}+y}{q}\right)-u\left(x^{*}\right)\right\}}{r+\alpha \gamma^{\prime}\left(W^{*}\right)\left\{u\left(\frac{r a^{*}+y}{q}\right)-u\left(x^{*}\right)\right\}}, \\
& a^{*}-a_{0}=-\Omega\left(W^{*}-W_{0}\right), \\
& \eta^{*}=v^{\prime}\left(c^{*}\right)-\left(1+\alpha \lambda^{*}\right) \frac{\gamma\left(W^{*}\right)}{q} u^{\prime}\left(\frac{r a^{*}+y}{q}\right) .
\end{aligned}
$$

To understand the determination of the steady-state solution, eliminate $\lambda^{*}$ from Eq. (28) by substituting Eq. (29). Using the resulting equation and Eq. (27), we can express consumption $x^{*}$ and $c^{*}$ as

$$
x^{*}=X\left(\begin{array}{l}
W_{(-)}^{*}, r a_{(+)}^{*}+y \\
(+)
\end{array}\right) \text { and } c^{*}=C\left(\begin{array}{l}
W_{(+)}^{*}, r a^{*}+y \\
(+)
\end{array}\right),
$$

where signs below the arguments indicate the signs of the corresponding partial derivatives. Substitution of $X$ for $x^{*}$ in Eq. (26) yields

$$
\alpha \gamma\left(W^{*}\right)\left\{u\left(\frac{r a^{*}+y}{q}\right)-u\left(X\left(W^{*}, r a^{*}+y ; q\right)\right)\right\}=\psi
$$

As Eq. (33) constrains $W^{*}$ and $a^{*}$ such that self-control costs (LHS) equals the constant rate of willpower net recovery (RHS), we call it the long-run willpower constraint (LWC).

We refer to Eq. (30) as the long-run saddle trajectory (LST). The LST goes through the initial value points $\left(W_{0}, a_{0}\right)$. The long-run willpower $W^{*}$ and wealth holdings $a^{*}$ are jointly determined at the intersection of LWC and LST. As illustrated graphically in "Appendix 5", the slopes of the two schedules depend on whether $x$ is a luxury $(\varepsilon>0)$ or an inferior $(\varepsilon<0)$ in two ways. First, from Eq. (21) and Property 3, the LST is negatively or positively sloping as $\varepsilon$ is positive or negative. Second, the relative magnitudes of the slopes of the two schedules depend on the sign of $\varepsilon$. The slope of LWC can be either positive or negative even when $\varepsilon$ takes a certain sign. It depends on the relative magnitudes of direct and indirect effects that willpower has on self-control costs: an increase in willpower directly reduces self-control costs (i.e., $\alpha \gamma^{\prime}<0$ ), which we call the SCC-reducing effect, hereafter, while it enlarges the costs indirectly by decreasing tempting good consumption, and hence, enlarging self-control requirement (i.e., $-\alpha \gamma X_{W}>0$ ), which we call the SCR-enlarging effect, hereafter. 
When $\varepsilon$ is positive, the slope of the LWC is negative or positive, as the negative SCCreducing effect dominates or is dominated by the positive SCR-enlarging effect. The opposite is true when $\varepsilon$ is negative.

In sum, the properties of $\left(W^{*}, a^{*}\right)$ depend on whether $x$ is a luxury or an inferior good and whether the SCC-reducing effect dominates, or is dominated by, the SCRenlarging effect. With $\left(W^{*}, a^{*}\right)$ determined at the intersections of the two schedules, the steady-state consumption basket $\left(x^{*}, c^{*}\right)$ is determined by Eq. (32), and the shadow prices $\lambda^{*}$ and $\eta^{*}$ are decided by Eqs. (29) and (31), respectively. Table 1 summarizes the long-run properties of the optimum solution by conducting comparative statics (see "Appendix 6" for the analytical results of the comparative statics). We shall discuss them briefly in the following two sections.

\section{Initial values of wealth and willpower}

As the long-run saddle trajectory (LST) depends on the initial values of $W_{0}$ and $a_{0}$, the consumer's long-run behavior is affected by the strength of willpower in earlier life stages and the wealth he was born into.

\subsection{Initial willpower}

An increase in initial willpower $W_{0}$ shifts the LST schedule to the right, and thereby, increases the long-run willpower $W^{*}$, as summarized in Table 1 . This is consistent with an empirical finding in psychology that self-control in one's early childhood predicts cognitive and self-regulatory competence in later stages (e.g., Shoda et al. 1990; Moffitt 2011). The result theoretically justifies the importance of upbringing and education in early childhood stressed in the empirical literature (e.g., Heckman 2006; Bucciol et al. 2010).

Note, however, that in our model with endogenous wealth holdings, stronger selfregulation owing to greater initial willpower may not result in moderation in tempting good consumption $x^{*}$, as the steady-state wealth holdings $a^{*}$, and hence, disposable income, may increase.

\subsection{Initial wealth}

As an increase in initial wealth $a_{0}$ shifts the LST schedule upward, its effect on the long-run self-control depends crucially on whether the tempting good is a luxury or an inferior good. When the tempting good is a luxury, a larger $a_{0}$ allows the consumer to indulge more in enjoying the tempting luxury in early periods and save the self-control resource for later. It follows that initially wealthy consumers will exhibit ceteris paribus stronger willpower in consuming tempting luxuries in the long run. This relationship might be more intuitive if restated as follows: an initially poor consumer will exhibit weaker willpower in consuming tempting luxuries in the long run. This is similar to the story of "parvenus", who indulge in consuming tempting luxuries that they had to moderate in their earlier poor life stages of relative poverty. 


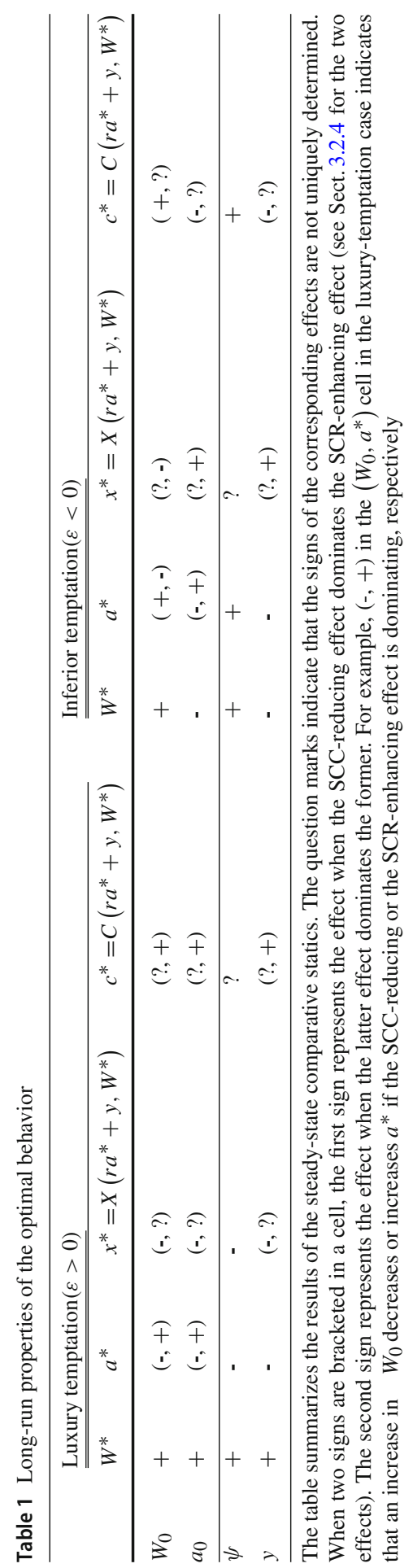


In contrast, when the tempting good is an inferior, initially poor consumers will be more self-regulated in consumption of the good in the long run because they indulge in consuming the inferior good in their earlier poor life stages, thereby saving self-control in the long run.

Property 5 In the long run, initially poorer consumers display weaker self-control in consuming tempting luxuries (parvenu effect), whereas exhibit stronger self-control in consuming tempting inferiors.

\section{Shifts in the long-run willpower constraint}

Let us next examine the effects that shifts in the LWC schedule have. To do so, we consider an exogenous increase in external needs for self-control, captured by a decrease in recovery rate $\psi$, and a negative income shock to endowed income level $y$. Subsequently, the steady-state point moves along the LST schedule. Unlike when the LST-schedule shifts, the substitutability/complementarity relationships between $W_{t}$ and $a_{t}$ that hold marginally along the transition path (see Property 3 ) are retained in the long run between $W^{*}$ and $a^{*}$. With a shift in the LWC, two budget variables $W^{*}$ and $a^{*}$ change in the opposite directions, as if they were substitutes, if $\varepsilon>0$, whereas they comove in the same directions as if they were complementary, if $\varepsilon<0$.

\subsection{External stressful shocks}

A typical nature of consumer behavior under limited self-control is that it is affected by outside stressful events that are supposedly irrelevant to consumption choices, e.g., troubles in human relationships, loss of family members, heart-break, etc. This effect is seen by supposing an exogenous decrease in recovery rate $\psi \cdot{ }^{14}$ As summarized in Table 1, the outside stressful event captured by a decrease in $\psi$ leads to reduction in long-run willpower. Given the reduction in $W^{*}$, wealth holdings $a^{*}$ increase or decrease, as the tempting good is a luxury $(\varepsilon>0)$ or an inferior $(\varepsilon<0)$, and hence, as $a^{*}$ is substitutable with, or complementary to $W^{*}$.

As tempting good consumption $x^{*}\left(=X\left(W^{*}, r a^{*}+y\right)\right)$ depends on $a^{*}$, the signs of the effect on $x^{*}$ also depend on whether it is a luxury or an inferior good. When it is a luxury, $x^{*}$ necessarily goes up with the stressful event. When it is an inferior good, in contrast, we cannot exclude the paradoxical possibility that the same shock leads to reduction in $x^{*}$ through decrease in $a^{*}$. Intuitively, in this case, the consumer reduces the self-control requirement $\sigma$, instead of reducing its unit cost, by reducing wealth holdings $a^{*}$, and hence, the temptation consumption level $x^{T *}$ (see Eq. (4)).

Note that irrespective of whether the effect on $x^{*}$ is positive or negative, $x_{t}$ necessarily exhibits an increasing time-path in the interim run. This occurs because a once-and-for-all stressful shock makes future willpower more scarce $\left(W_{t}>W^{*}\right)$, and thereby, makes the consumer temporarily patient in consuming $x$ in the interim run

\footnotetext{
14 The recovery rate $\psi$ can be taken as the gross recovery rate netted of exogenous self-control cost payments. We are here considering an increase in the exogenous self-control cost payment.
} 
(see (i) in Property 4). As the scarcity of willpower gradually increases due to mental fatigue over time, the consumer loses patience in consuming $x$.

Proposition 3 A permanent stressful shock weakens a consumer's willpower in the long run. Along with the increasing scarcity of willpower, self-indulgence and impatience for tempting good consumption increase over time.

Remark 3 The reduction in willpower due to an exogenous stressful shock is consistent with the existing empirical reports that an increase in external burden on self-control results in loss of self-regulatory power in decision-making (Shiv and Fedorikhin 1999). On the other hand, a low $\delta^{x}$, compared to $r$, in the interim run appears to be inconsistent with the empirical results that experimentally imposed stress tasks lead to rises in participants' subjective discount rates for money (Hinson et al. 2003; Fields et al. 2014), if money is a tempting good. This apparent contradiction occurs because the stressful shock under consideration here is a once-and-for-all shock, which makes current self-control less scarce than in future. In contrast, experimentally imposed stress shocks are temporary, in which case current self-control would become scarcer than in future, so that impatience temporarily increases.

\subsection{Negative income shock}

Consider a permanent decrease in endowment income $y$. From Eqs. (32) and (33), it shifts the LWC schedule downward and definitely increases $a^{*}$, implying that the consumer mitigates the effect of the negative income shock on the budget by increasing wealth holdings through savings. The effect on $W^{*}$ is negative or positive as $x$ is a luxury or an inferior, and hence, as $W^{*}$ is substitutable with, or complementary to $a^{*}$.

Paradoxically, Table 1 suggests the possibility that $x^{*}$ increases after the negative income shock even when the tempting good is marginally a luxury $(\varepsilon>0)$. This can happen for two reasons. First, a decrease in $y$ can increase the steady-state disposable income $r a^{*}+y$ through the enhancing effect on $a^{*}$. It can be shown that $d\left(r a^{*}+y\right) / d y$ is positive or negative, as the SCC-reducing effect of self-control is smaller or larger than the SCR-enlarging effect. Thus, with the dominating SCCreducing effect, the negative income shock leads to an increase in the long-run disposable income, which has a positive effect on $x^{*}$. Second, when $\varepsilon>0, W^{*}$ falls after the shock, which again has a positive effect on $x^{*}$. It follows that a negative income shock increases tempting good consumption if the SCC-reducing effect of self-control dominates the SCR-enlarging effect and if the tempting good is a luxury. ${ }^{15}$

\section{Naive consumers}

We have so far considered a sophisticated consumer who incorporates the willpower constraint completely in decision-making. However, actual consumers often display

\footnotetext{
15 When $\varepsilon=0$, the LWC schedule becomes a vertical line, whereas the LST line becomes a horizontal line. An external stressful shock, i.e., a decrease in $\psi$, makes the LWC schedule shift leftward, thereby lowers $W^{*}$ and hence shifts consumption from $c^{*}$ to $x^{*}$. A negative income shock, i.e., a decrease in $y$, does not affect LWC nor LST. The shock increases both $c^{*}$ and $x^{*}$. For the formal results, see Appendix 6.
} 
the naivety and do not incorporate the willpower constraint completely, failing to efficiently exercise self-control. We shall examine the effect of such naiveté.

\subsection{Naive dynamics}

Consider a completely naive consumer who does not incorporate the flow budget equation for willpower (8) into his decision-making at all. We call him consumer $N$. He derives utility from the same utility function (2) as the sophisticated consumer (consumer $S$, hereafter) would do, but is not aware that it actually depends on his willpower level. He takes the influences of variations in willpower on utility as external preference shifts. ${ }^{16}$

We denote naive consumer $N$ by superscript $N$. His utility maximization problem can be expressed as the one to maximize the following current-value Hamiltonian function $H_{t}^{N}$ at each point in time $t$, instead of (11):

$$
H_{t}^{N}=v\left(c_{t}^{N}\right)+\left(1+\gamma_{t}\right) u\left(x_{t}^{N}\right)+\eta_{t}^{N}\left(r a_{t}^{N}+y-q x_{t}^{N}-c_{t}^{N}\right),
$$

where the value of $\gamma_{t}$ is given by $\gamma\left(W_{t}^{N}\right)$, which he mistakes as a constant. ${ }^{17}$

The optimality conditions at time $t$ are thus given by

$$
\begin{aligned}
& v^{\prime}\left(c_{t}^{N}\right)=\eta_{t}^{N}, \\
& \frac{\left\{1+\gamma\left(W_{t}^{N}\right)\right\} u^{\prime}\left(x_{t}^{N}\right)}{v^{\prime}\left(c_{t}^{N}\right)}=q, \\
& \dot{\eta}_{t}^{N}=0,
\end{aligned}
$$

together with Eq. (1), in which superscript $N$ is added to each variable, and the transversality condition for $a^{N}$. Based on these conditions, consumer $N$ at time $t$ makes an entire lifetime consumption plan, and actually consumes $\left(x_{t}^{N}, c_{t}^{N}\right)$ at that time according to the plan. However, as willpower and hence $\gamma_{t}\left(=\gamma\left(W_{t}^{N}\right)\right)$ evolve over time, the lifetime plan will be overwritten.

16 The notion of naiveté here is different from that in the present-bias literature, in which naiveté is defined as being unaware of future occurrence of self-control problems (O’Donoghue and Rabin 1999; Ojima 2018; Liu et al. 2020). Our naive consumer is unaware of the fact that the self-control unit costs $\gamma$ vary due to willpower variations. This can lead to underestimation or overestimation of future self-control costs as willpower decreases or increases in the future.

17 As consumer $N$ at time $t$ regards $\gamma_{t}$ as constant over time, the discussion in footnote 7 implies that his lifetime utility at that time is given by

$$
\int_{t}^{\infty}\left\{u\left(x_{s}^{N}\right)+\left(1+\gamma_{t}\right) v\left(c_{s}^{N}\right)\right\} \exp (-r(s-t)) d s-\gamma_{t} V\left(a_{t}^{N}\right) .
$$

Note that $V\left(a_{t}^{N}\right)$ cannot be controlled at time $t$, because $a_{t}^{N}$ is historically determined. The problem for consumer $N$ at time $t$ to maximize the lifetime utility can be expressed as the one to maximize $H_{S}^{N}$, defined in the text, for each $s \geq t$, where $\gamma_{s}$ is fixed at $\gamma_{t}$. 
From Eqs. (34) to (36) and the transversality condition, consumer $N$ at time $t$ plans to keep $\left(x_{t}^{N}, c_{t}^{N}, a_{t}^{N}\right)$ constant over time, such that saving is kept zero $\left(\dot{a}_{t}^{N}=0\right)$ :

$$
r a_{0}^{N}+y=q x_{t}^{N}+c_{t}^{N}
$$

where $a_{t}^{N}$ is set equal to the initial value $a_{0}^{N}$. The time- $t$ consumption $\left(x_{t}^{N}, c_{t}^{N}\right)$ is determined from Eqs. (35) and (37). Eliminating $c_{t}$ from the two equations yields

$$
\frac{\left\{1+\gamma\left(W_{t}^{N}\right)\right\} u^{\prime}\left(x_{t}^{N}\right)}{v^{\prime}\left(r a_{0}^{N}+y-q x_{t}^{N}\right)}=q
$$

which can be solved for $x_{t}^{N}$. Substituting it to Eq. (37) yields the solution for $c_{t}^{N}$. We express the results as

$$
x_{t}^{N}=X^{N}\left(\begin{array}{c}
W_{t}^{N} ; r a_{0}^{N}+y \\
(-)
\end{array} \underset{(+)}{N}\right) \text { and } c_{t}^{N}=X^{N}\left(\begin{array}{c}
W_{t}^{N} ; r a_{0}^{N}+y \\
(+)
\end{array}\right) .
$$

Note that different from Eq. (32), behavioral relation (39) does not represent optimal strategic responses to willpower changes: instead, it captures unexpected adaptive adjustments to preference shifting due to unconscious willpower changes. We obtain the autonomous willpower dynamics that are external to consumer $N$ by substituting Eq. (39) into Eq. (8) as

$$
\dot{W}_{t}^{N}=\psi-\alpha \gamma\left(W_{t}^{N}\right)\left\{u\left(\frac{r a_{0}^{N}+y}{q}\right)-u\left(X^{N}\left(W_{t}^{N} ; r a_{0}^{N}+y\right)\right)\right\} .
$$

Letting $\Pi$ denote

$$
\begin{aligned}
\Pi \equiv & \gamma\left(W^{N}\right) u^{\prime}\left(x^{N}\right)^{2} \\
& +\left\{u\left(\frac{r a_{0}^{N}+y}{q}\right)-u\left(x^{N}\right)\right\}\left[\left\{1+\gamma\left(W^{N}\right)\right\} u^{\prime \prime}\left(x^{N}\right)+q^{2} v^{\prime \prime}\left(c^{N}\right)\right],
\end{aligned}
$$

the necessary and sufficient condition for the stability $d \dot{W} / d W<0$ is

$$
\Pi>0 \text {. }
$$

Assumption 3 The external willpower dynamics for the naive consumer (40) are stable: $\Pi>0$.

As in the case of sophisticated consumers, an increase in $W^{N}$ has a direct negative SCC-reducing effect on the self-control cost through $\alpha \gamma\left(W_{t}^{N}\right)$ and an indirect positive SCR-enlarging effect on it through $-u\left(X^{N}\left(W_{t}^{N}\right)\right)$. Assumption 3 requires that the SCR-enlarging effect dominates the SCC-reducing effect. 


\subsection{The naiveté effect}

We obtain the long-run optimal solution for the naive consumer by setting $\dot{W}^{N}=0$ in Eq. (40). The resulting long-run self-control constraint

$$
\alpha \gamma\left(W^{N *}\right)\left\{u\left(\frac{r a^{N *}+y}{q}\right)-u\left(X^{N}\left(W^{N *} ; r a^{N *}+y\right)\right)\right\}=\psi
$$

determines $W^{N *}$, in which we set $a^{N *}=a_{0}^{N}$ from the zero net-saving condition, Eq. (37). Given the $W^{N *}$ value, $x^{N *}$ and $c^{N *}$ are given from Eq. (39).

To observe how self-control inefficiency due to naiveté affects consumer behavior, compare consumers $N$ and $S$ who are identical in preferences and income $y$. A close look at Eqs. (28) and (38) reveals

$$
X^{N}\left(W^{N *} ; r a^{N *}+y\right)<X\left(W^{*} ; r a^{*}+y\right) \text { if }\left(W^{N *}, a^{N *}\right)=\left(W^{*}, a^{*}\right),
$$

where the sophisticate's tempting good consumption function $X$ is given by Eq. (32). That is, in steady state, with the same willpower stock and the same wealth holdings, consumer $N$ would keep the level of the tempting good consumption lower than consumer $S$ would do, meaning that consumer $N$ unconsciously exercises too much self-control.

Let us define the left-hand side of Eq. (42) as the steady-state self-control cost function for the naive consumer $Z^{N}\left(W^{N *}, a^{N *}\right)$. The corresponding function $Z\left(W^{*}, a^{*}\right)$ for the sophisticated consumer is given by the left-hand side of Eq. (33). From inequality (43), if $\left(W^{N *}, a^{N *}\right)=\left(W^{*}, a^{*}\right)$, we have

$$
\begin{aligned}
& Z\left(W^{*}, a^{*}\right)-Z^{N}\left(W^{N *}, a^{N *}\right) \\
& \quad=\alpha \gamma\left(W^{*}\right)\left\{u\left(X^{N}\left(W^{N *} ; r a^{N *}+y\right)\right)-u\left(X\left(W^{*}, r a^{*}+y\right)\right)\right\} \\
& \quad<0,
\end{aligned}
$$

meaning that without difference in willpower and wealth between consumers $S$ and $N$, $N$ should incur greater self-control costs in the long run than $S$ would. As the values of $Z$ and $Z^{N}$ should commonly equal $\psi$ in the steady state, this inequality should be cleared by the adjustments of steady-state values of willpower and/or wealth holdings. From Eq. (41), we have $d Z^{N} / d W^{N}>0$. It follows that, if $a^{N *}=a^{*}$, that is, if the two are in the same wealth class, $W^{N *}$ should be smaller than $W^{*}$. From Eqs. (33) and (42), this in turn implies that $x^{N *}$ is larger than $x^{*}$.

Proposition 4 Naive consumer $N$ has weaker willpower and consumes more tempting goods than sophisticated consumer $S$ in the steady state if they are in the same wealth class:

$$
W^{N *}<W^{*} \text { and } x^{N *}>x^{*} \text { if } a^{N *}=a^{*} .
$$


Remark 4 As seen from discussions in Sect. 4, by choosing initial values, e.g., $a_{0}^{N}$ and $a_{0}$, we can necessarily construct consumers $N$ and $S$ with the same utility function and the same steady-state wealth holding, $a^{N *}=a^{*}$.

Similarly, we can consider the effect of being naive on wealth holdings by comparing consumers $N$ and $S$ with the same willpower stock: $W^{N *}=W^{*}$, where as discussed in Remark 4 we can construct such consumers by choosing initial values. We can show that, as $x$ is a luxury $(\varepsilon>0)$ or an inferior $(\varepsilon<0)$, an increase in $a^{*}$ ceteris paribus decreases or increases the self-control requirement $u\left(\frac{r a^{*}+y}{q}\right)-u\left(X\left(W^{*}, r a^{*}+y\right)\right)$ and hence self-control cost $Z$.

Suppose that the two consumers have the same level of willpower. Then, due to inefficient usage of willpower, consumer $N$ cannot incur self-control costs as much as consumer $S$ could. Thus, when $x$ is a luxury, consumer $N$ should be wealthier than consumer $S$ so as to consume greater tempting luxury and thereby keep the self-control requirement lower.

In contrast, when $x$ is an inferior good, consumer $N$ must be poorer than consumer $S$ to keep the temptation consumption level $x^{T N}$ lower, which leads to lower self-control requirement in the inferior temptation case.

Formally, under stability condition (41), we derive the following result.

Proposition 5 The steady-state solution satisfies the following:

1. Tempting luxury case $(\varepsilon>0)$ : Naive consumer $N$ is richer and consumes more tempting goods than sophisticated consumer $S$ if they have the same willpower stock:

$$
a^{N *}>a^{*} \text { and } x^{N *}>x^{*} \text { if } W^{N *}=W^{*} .
$$

2. Tempting inferior case $(\varepsilon<0)$ : Naive consumer $N$ is poorer and consumes less tempting goods than sophisticated consumer $S$ if they have the same willpower stock:

$$
a^{N *}<a^{*} \text { and } x^{N *}<x^{*} \text { if } W^{N *}=W^{*} .
$$

Intuitively, when the two consumers have the same level of the willpower resource, consumer $N$ is effectively poorer in willpower than consumer $S$. In the luxury temptation case, willpower and wealth are substitutes. Thus, consumer $N$, who is effectively poorer in willpower, should have greater wealth. In the inferior case, where the two capital resources are complementary, consume $N$ must have smaller wealth than consumer $S$.

Remark 5 As reported by Kivetz and Keinan (2006), consumers tend to regret on having exercised too much self-control when retrospecting that they chose a virtuous non-tempting item (e.g., eating a fruit salad, working) rather than a vicious temptation (e.g., eating chocolate, partying) in the distant past. From Propositions 4 and 5, our naive consumer model could be related to this tendency in two ways. First, by retrospecting the past decision making, naive consumers will find regretfully that, for 
the given realized time profile of preferences, their consumption plans for tempting goods were too moderate. Second, although consumers are assumed to remain naive, they in reality may be able to become more sophisticated through learning. After the long-run learning process, they would be sophisticated enough to feel regret about having allocated self-control inefficiently.

\section{Comparison to alternative specifications}

\subsection{Constant temptation consumption level $x^{T}$}

We have specified the temptation utility by Eq. (3) to endogenize the temptation consumption level $x^{T}$. Instead, consider the case that $x^{T}$ is constant, as assumed in Ozdenoren et al. (2012). Then, as seen by setting $u^{\prime}\left(x^{T}\right)=0$ in Eqs. (17) and (19), the tempting good is necessarily a luxury $(\varepsilon>0)$, whereas the non-tempting good consumption is perfectly smoothed $(\dot{c}=0)$. This implies that endogenous $x^{T}$ plays a critical role in interactions between tempting and non-tempting consumption and the resulting non-smoothed consumption not only for tempting goods but also for non-tempting goods.

To describe interactive consumption for two goods (cake eating and completing a work) under a constant temptation consumption level, Ozdenoren et al. (2012) assumes that self-regulatory effort is necessary both for controlling cake eating and completing the work. This brings about direct substitutability between the two good consumption under limited willpower. Without such a specification, our model shows that endogenous $x^{T}$ generates interactive and non-smoothed consumption for tempting and non-tempting goods.

\subsection{Adding willpower-enhancing effects of self-control}

We have implicitly assumed that self-regulatory efforts just reduce willpower, but do not enhance it. This assumption may be limited compared to the evidence that willpower is malleable (Muraven et al. 1999). In "Appendix 7", we weaken it by considering that self-regulation in moderating tempting good consumption has a willpower-enhancing effect as well as a willpower-depreciating effect. The property of the solution would depend crucially on the relative magnitudes of the two countervailing effects. If the willpower-enhancing effect were much greater than the willpower-depleting effect, consumers with weaker willpower might moderate their consumption of tempting goods more patiently to enhance their future willpower; therefore, consumer behavior relates to willpower in opposite ways to our predictions, which are obtained under the dominant willpower-depreciating effect.

Which prediction is actually correct is an empirical issue. As long as concerned with short-term behaviors, the prediction in the dominant willpower-enhancing effect case seems not only implausible but also inconsistent with empirical facts. For example, in that case, when the independent self-control requirement shifts upward for the tempting luxury $(\varepsilon>0)$, tempting good consumption decreases and willpower level 
becomes higher over time. This is inconsistent with the fact that increases in external burden on self-regulation fatigue consumers, and thereby, reduce their self-regulatory power (see, e.g., Shiv and Fedorikhin 1999; Hinson et al. 2003).

\subsection{Myopic affective self}

Gul and Pesendorfer (2004) proposes a model of simple consumer preferences, in which the consumer is tempted to maximize the current temptation utility, rather than intertemporal temptation utility like Eq. (3). The temptation consumption level there equals total wealth. We call it a model of the myopic affective self. By setting $x_{t}^{T}$ equal to total wealth $\left(a_{t}+y / r\right) / q$, consider the myopic affective self in our two good framework. The time- $t$ self-control requirement (6) is then replaced by $\sigma_{t}=$ $u\left(\left(a_{t}+y / r\right) / q\right)-u\left(x_{s}\right)$, because the myopic affective self does not derive felicity from saving $\dot{a}_{t}$. By denoting the primitive discount rate by $\rho(>0)$, we can specify the consumer's lifetime utility as

$$
\int_{0}^{\infty}\left[u\left(x_{t}\right)+v\left(c_{t}\right)-\gamma\left(W_{t}\right)\left\{u\left(\frac{a_{t}+y / r}{q}\right)-u\left(x_{t}\right)\right\}\right] \exp (-\rho t) d t .
$$

The consumer solves the problem that is obtained by replacing Eq. (9) with Eq. (44) in Problem (P).

By applying the usual Hamiltonian approach, ${ }^{18}$ we can reduce the optimum conditions into a fourth-order system of differential equations. Although it is prohibitively challenging to obtain analytical solutions, we can see several properties of the solutions. ${ }^{19}$ First, as conjectured from Eq. (44), the marginal rate of net return on wealth is endogenously determined as $r$ minus a marginal increase in self-control costs depending on $u^{\prime}\left(\frac{a^{*}+y / r}{q}\right)$. We can thus obtain a steady-state solution, if any, even when $\rho$ does not equal $r$. However, for a steady-state solution to exist, the discount rate $\rho$ should be lower than the interest rate $r$, i.e., the consumer under temptation should be more patient than the market in the long run. Second, the resulting steady state would be independent of the initial value, unlike in our model. This might be a desirable property when describing usual economic dynamics. However, the property seems rather incompatible with the empirical evidence that adults' self-control competency depends crucially on personal history in their early life stage (Shoda et al. 1990; Moffitt 2011; Miller et al. 2015). Third, numerical steady-state solutions show that a higher discount rate $\rho$ leads to greater steady-state wealth $a^{*}$. This is because a high $\rho$ should be matched by a high net return on $a^{*}$ and hence by a low marginal cost of selfcontrol $u^{\prime}\left(\frac{a^{*}+y / r}{q}\right)$, implying a large $a^{*}$. Fourth, by examining numerical solutions, we find that the stable solution is difficult to obtain insofar as the relative risk aversion parameter is set greater than unity as in the empirical literature.

\footnotetext{
18 Irrespective of that the affective self is myopic while the deliberative self cares about the entire future felicity stream with a finite discount rate $\rho$, the preference in Eq. (44) is time-consistent. This is because the deliberative self incorporates correctly the future time profile of the temptation level $x^{T}$ when making decisions at each instant of time.

19 The analytical details are available upon request.
} 


\section{Conclusions}

Using a model with fatiguing self-regulation, we describe consumer behavior from the integrated viewpoint of (1) intratemporal choices between tempting and non-tempting goods, (2) intertemporal consumption/saving choices, and (3) intertemporal allocation of self-regulation. The degree of impatience implied from optimal consumption choices depends on how tempting the domain good is; whether the tempting good is a luxury or an inferior; how wealthy the consumer is; and whether he is sophisticated or naive. The solution describes asymmetric consumer behaviors toward tempting luxuries and tempting inferiors in an empirically-relevant way. In particular, we show that richer consumers are more self-indulgent and, under weak conditions, more impatient for tempting luxuries, whereas they are less so for tempting inferiors. Naive consumers that are unaware of the willpower constraint will exhaust their willpower and indulge in tempting consumption in the steady state more than the sophisticated consumers would.

Note that, in producing these results, willpower-dependent self-control costs play a critical role. Without either temptation utility or willpower-dependence, the nonhomotheticity would disappear, so that the model would be reduced to a simple one of the permanent income theory.

We leave several tasks undone. First, it is important to provide an axiomatic foundation to the model. After Fudenberg and Levine (2006) points out that the convex structure of self-control costs violates the independent axiom in Gul and Pesendorfer $(2001,2004)$, there are a few attempts to axiomatize the temptation model with convex self-control costs under limited willpower (Noor and Takeoka 2010, Liang et al. 2020, Masatlioglu et al. 2020). However, they are limited to static or at most two-period settings. To give a micro-foundation to our model, it is necessary to extend their insights into a multi-period framework with endogenous willpower. Second, the primitive discount rates for tempting and non-tempting goods are assumed to equal the interest rate. Even to capture the hysteresis property of self-control competency, more sophisticated modelling should be devised. Third, "Appendix 7" specifies an extended model by simply assuming that the willpower-depleting and -enhancing effects of self control commonly occur instantly. A longer delay is more plausible for the willpowerenhancing effect than for the willpower-depleting effect. In such a realistic setting, a self-regulatory behavior would exert non-monotonic effects on consumers' decisionmaking, leading to cyclical behaviors. Fourth, the definition of naiveté here is limited. Defining naiveté about self-control capability in a more general framework would be an interesting topic. For example, Ahn et al. (2020) proposes an axiomatic definition of naivete in the presence of temptation. However, their work is limited to the case of constant self-control unit costs, and cannot be applied to our model with variable $\gamma \cdot{ }^{20}$ Fifth, by extending the model into a general equilibrium framework, we could remove the ad hoc assumption that the discount rate equals $r$. In the temptation model,

\footnotetext{
20 Ahn et al. (2020) characterizes naiveté as the property that the future self-control unit costs are underestimated. In contrast, naive consumers here under- or over-estimate future $\gamma$ depending on whether their willpower is decreasing or increasing over time (see footnote 16).
} 
endogenous price variables would affect the temptation consumption level. This may generate richer consumer dynamics.

Open Access This article is licensed under a Creative Commons Attribution 4.0 International License, which permits use, sharing, adaptation, distribution and reproduction in any medium or format, as long as you give appropriate credit to the original author(s) and the source, provide a link to the Creative Commons licence, and indicate if changes were made. The images or other third party material in this article are included in the article's Creative Commons licence, unless indicated otherwise in a credit line to the material. If material is not included in the article's Creative Commons licence and your intended use is not permitted by statutory regulation or exceeds the permitted use, you will need to obtain permission directly from the copyright holder. To view a copy of this licence, visit http://creativecommons.org/licenses/by/4.0/.

\section{Appendix 1: Derivation of Eq. (7)}

Substituting Eq. (6) into the left-hand sides of Eq. (7), we have

$$
\begin{aligned}
\int_{t}^{\infty} \sigma_{s} \exp (-r(s-t)) d s= & \int_{t}^{\infty} u\left(x_{s}^{T}\right) \exp (-r(s-t)) d s \\
& -\int_{t}^{\infty} u\left(x_{s}\right) \exp (-r(s-t)) d s \\
& -\int_{t}^{\infty} u^{\prime}\left(x_{s}^{T}\right) \frac{\dot{a}_{s}}{q} \exp (-r(s-t)) d s .
\end{aligned}
$$

By using partial integration, the last term on the right-hand side of Eq. (45) can be expressed as

$$
\begin{aligned}
\int_{t}^{\infty} u^{\prime}\left(x_{s}^{T}\right) \frac{\dot{a}_{s}}{q} \exp (-r(s-t)) d s & =0-\frac{u\left(x_{t}^{T}\right)}{r}+\int_{t}^{\infty} u\left(x_{s}^{T}\right) \exp (-r(s-t)) d s \\
& =\int_{t}^{\infty} u\left(x_{s}^{T}\right) \exp (-r(s-t)) d s-V\left(a_{t}\right) .
\end{aligned}
$$

Substituting this equation into Eq. (45) yields Eq. (7):

$$
\int_{t}^{\infty} \sigma_{s} \exp (-r(s-t)) d s=V\left(a_{t}\right)-\int_{t}^{\infty} u\left(x_{s}\right) \exp (-r(s-t)) d s .
$$

\section{Appendix 2: Derivation of Eq. (17)}

Linearizing Eq. (16) around the steady state gives us

$$
\begin{aligned}
c_{t}-c^{*}= & \frac{\{1+(1+\alpha \lambda) \gamma\} u^{\prime \prime}(x)}{q v^{\prime \prime}}\left(x_{t}-x^{*}\right) \\
& +\frac{u^{\prime}(x)}{q v^{\prime \prime}}\left\{(1+\alpha \lambda) \gamma^{\prime}\left(W_{t}-W^{*}\right)+\alpha \gamma\left(\lambda_{t}-\lambda^{*}\right)\right\} .
\end{aligned}
$$


On the other hand, Eqs. (12) and (15) are linearized to, respectively,

$$
\begin{aligned}
\{1+(1+\alpha \lambda) \gamma\} u^{\prime \prime}(x)\left(x_{t}-x^{*}\right)= & -\left\{u^{\prime}(x)-u^{\prime}\left(x^{T}\right)\right\}(1+\alpha \lambda) \gamma^{\prime}\left(W_{t}-W^{*}\right) \\
& -\left\{u^{\prime}(x)-u^{\prime}\left(x^{T}\right)\right\} \alpha \gamma\left(\lambda_{t}-\lambda^{*}\right) \\
& +(1+\alpha \lambda) \gamma u^{\prime \prime}\left(x^{T}\right) \frac{r}{q}\left(a_{t}-a^{*}\right)+q\left(\eta_{t}-\eta^{*}\right), \\
q \dot{\eta}_{s}= & -(1+\alpha \lambda) \gamma u^{\prime \prime}\left(x^{T}\right) \frac{r}{q} \dot{a}_{s} .
\end{aligned}
$$

For the sake of convenience, we replace subscript $t$ with $s$ in Eq. (48). Integrating Eq. (48) with respect to $s$ from $t$ to infinity, we have

$$
q\left(\eta_{t}-\eta^{*}\right)=-(1+\alpha \lambda) \gamma u^{\prime \prime}\left(x^{T}\right) \frac{r}{q}\left(a_{t}-a^{*}\right) .
$$

Substituting this for $q\left(\eta_{t}-\eta^{*}\right)$ in Eq. (47) results in

$$
\begin{aligned}
& \{1+(1+\alpha \lambda) \gamma\} u^{\prime \prime}(x)\left(x_{t}-x^{*}\right) \\
& \quad=-\left\{u^{\prime}(x)-u^{\prime}\left(x^{T}\right)\right\}\left\{(1+\alpha \lambda) \gamma^{\prime}\left(W_{t}-W^{*}\right)-\alpha \gamma\left(\lambda_{t}-\lambda^{*}\right)\right\} .
\end{aligned}
$$

Combining Eq. (46) with Eq. (49) to eliminate the term $(1+\alpha \lambda) \gamma^{\prime}\left(W_{t}-W^{*}\right)-$ $\alpha \gamma\left(\lambda_{t}-\lambda^{*}\right)$, we obtain

$$
c_{t}-c^{*}=-\frac{\{1+(1+\alpha \lambda) \gamma\} u^{\prime \prime}(x) u^{\prime}\left(x^{T}\right)}{q v^{\prime \prime}\left\{u^{\prime}(x)-u^{\prime}\left(x^{T}\right)\right\}}\left(x_{t}-x^{*}\right) .
$$

Using Eq. (28), the coefficient of $x_{t}$ in the above equation can be expressed as

$$
\begin{aligned}
-\frac{\{1+(1+\alpha \lambda) \gamma\} u^{\prime \prime}(x) u^{\prime}\left(x^{T}\right)}{q v^{\prime \prime}\left\{u^{\prime}(x)-u^{\prime}\left(x^{T}\right)\right\}} & =-\frac{v^{\prime} u^{\prime \prime}(x) u^{\prime}\left(x^{T}\right)}{u^{\prime}(x) v^{\prime \prime}\left\{u^{\prime}(x)-u^{\prime}\left(x^{T}\right)\right\}} \\
& =-\frac{\theta^{c} c^{*}}{\theta^{x} x^{*}}\left(\frac{u^{\prime}\left(x^{T}\right)}{u^{\prime}(x)-u^{\prime}\left(x^{T}\right)}\right),
\end{aligned}
$$

from which Eq. (17) follows.

\section{Appendix 3: Derivation of the dynamic system}

$-\dot{x}_{t}$ equation

Differentiating Eq. (47) by $t$ yields

$$
\begin{aligned}
\{1+ & (1+\alpha \lambda) \gamma\} u^{\prime \prime}(x) \dot{x}_{t}+(1+\alpha \lambda)\left\{u^{\prime}(x)-u^{\prime}\left(x^{T}\right)\right\} \gamma^{\prime} \dot{W}_{t} \\
& +\alpha \gamma\left\{u^{\prime}(x)-u^{\prime}\left(x^{T}\right)\right\} \dot{\lambda}_{t}-q \dot{\eta}-(1+\alpha \lambda) \gamma u^{\prime \prime}\left(x^{T}\right) \frac{r}{q} \dot{a}_{t}
\end{aligned}
$$




$$
=0 \text {. }
$$

From the linearized version of this equation, we shall show that $\dot{x}_{t}$ depends only on $x_{t}-x^{*}$ and $W_{t}-W^{*}$. First, because of Eq. (48), the terms of $\dot{\eta}_{t}$ and $\dot{a}_{t}$ on the LHS of Eq. (50) are cancelled out. Second, substitute Eqs. (10) and (14) for $\dot{W}_{t}$ and $\dot{\lambda}_{t}$ in Eq. (50), respectively. Although the two equations are expressed as functions of $x_{t}, W_{t}, \lambda_{t}$ and $a_{t}$, their linearized versions do not depend on $a_{t}-a^{*}$, because, around the steady state, we have

$$
\begin{aligned}
& \left.\frac{\partial \dot{W}_{t}}{\partial a_{t}}\right|_{(10)}=-\alpha \gamma\left\{u^{\prime}\left(x^{T}\right) \frac{r}{q}-u^{\prime}\left(x^{T}\right) \frac{r}{q}\right\}=0, \\
& \left.\frac{\partial \dot{\lambda}_{t}}{\partial a_{t}}\right|_{(14)}=(1+\alpha \lambda) \gamma^{\prime}\left\{u^{\prime}\left(x^{T}\right) \frac{r}{q}-u^{\prime}\left(x^{T}\right) \frac{r}{q}\right\}=0 .
\end{aligned}
$$

Third, we can eliminate $\lambda_{t}-\lambda^{*}$ by using Eq. (49). Consequently, we have the $\dot{x}$ equation

$$
\begin{aligned}
\dot{x}_{t}= & {\left[r+\alpha \gamma^{\prime}\left\{u\left(x^{T}\right)-u(x)\right\}\right]\left(x_{t}-x^{*}\right) } \\
& +\Delta\left\{u^{\prime}(x)-u^{\prime}\left(x^{T}\right)\right\}\left(W_{t}-W^{*}\right),
\end{aligned}
$$

where

$$
\Delta=\frac{-\gamma^{\prime} r+\alpha(1+\alpha \lambda)\left\{u\left(x^{T}\right)-u(x)\right\}\left(\gamma \gamma^{\prime \prime}-\gamma^{\prime 2}\right)}{-\{1+\gamma(1+\alpha \lambda)\} u^{\prime \prime}(x)} .
$$

- $\dot{W}_{t}$ equation

Eq. (10) is linearized as

$$
\begin{aligned}
\dot{W}_{t}= & \alpha \gamma\left\{u^{\prime}(x)-u^{\prime}\left(x^{T}\right)\right\}\left(x_{t}-x^{*}\right) \\
& -\alpha \gamma^{\prime}\left\{u^{\prime}(x)-u^{\prime}\left(x^{T}\right)\right\}\left(W_{t}-W^{*}\right)-\alpha \gamma u^{\prime}(x) \frac{1}{q}\left(c_{t}-c^{*}\right) .
\end{aligned}
$$

Eliminate $c_{t}-c^{*}$ by substituting Eq. (17). Rearrangement yields the $\dot{W}_{t}$ equation

$$
\dot{W}=\alpha \gamma\left\{u^{\prime}(x)-\varepsilon u^{\prime}\left(x^{T}\right)\right\}\left(x_{t}-x^{*}\right)-\alpha \gamma^{\prime}\left\{u\left(x^{T}\right)-u(x)\right\}\left(W_{t}-W^{*}\right) .
$$

$-\dot{a}_{t}$ equation

Equation (1) is linearized as

$$
\dot{a}_{t}=r\left(a_{t}-a^{*}\right)-q\left(x_{t}-x^{*}\right)-\left(c_{t}-c^{*}\right) .
$$


Eliminating $c_{t}-c^{*}$ by substituting Eq. (17), we have

$$
\dot{a}_{t}=r\left(a_{t}-a^{*}\right)-q \varepsilon\left(x_{t}-x^{*}\right) .
$$

- Saddle-point stability condition and unique optimum dynamics

Equations (51), (52) and (53) are summarized as the three-dimensional autonomous system:

$$
\begin{aligned}
\left(\begin{array}{c}
\dot{x}_{t} \\
\dot{W}_{t}
\end{array}\right) & =M\left(\begin{array}{c}
x_{t}-x^{*} \\
W_{t}-W^{*}
\end{array}\right), \\
\dot{a}_{t} & =r\left(a_{t}-a^{*}\right)-q \varepsilon\left(x_{t}-x^{*}\right) .
\end{aligned}
$$

where

$$
M=\left(\begin{array}{cc}
r+\alpha \gamma^{\prime}\left\{u\left(x^{T}\right)-u(x)\right\} & \Delta\left\{u^{\prime}(x)-u^{\prime}\left(x^{T}\right)\right\} \\
\alpha \gamma\left\{u^{\prime}(x)-\varepsilon u^{\prime}\left(x^{T}\right)\right\} & -\alpha \gamma^{\prime}\left\{u\left(x^{T}\right)-u(x)\right\}
\end{array}\right) .
$$

As $x$ is jumpable and $W$ is not, the local dynamics of Eq. (54) is stable and uniquely determined if and only if it is saddle-point stable, and hence, the determinant $\Phi$ of matrix $M$ is strictly negative:

$$
\Phi<0
$$

where

$$
\begin{aligned}
\Phi= & -\alpha \gamma^{\prime}\left[r+\alpha \gamma^{\prime}\left\{u\left(x^{T}\right)-u(x)\right\}\right]\left\{u\left(x^{T}\right)-u(x)\right\} \\
& -\alpha \gamma \Delta\left\{u^{\prime}(x)-u^{\prime}\left(x^{T}\right)\right\}\left\{u^{\prime}(x)-\varepsilon u^{\prime}\left(x^{T}\right)\right\} .
\end{aligned}
$$

With this saddle-point stability condition, the optimum dynamics is driven by the first-order differential equation for $W_{t}$ governed by the unique stable root $\chi$ of coefficient matrix $M$ :

$$
\dot{W}_{t}=\chi\left(W_{t}-W^{*}\right)
$$

\section{- Sufficient conditions for saddle-point stability}

To show a parametric example of sufficient conditions for saddle-point stability, we begin with specifying utility functions $u(x)$ and $v(c)$ and the self-control effort cost $\gamma(W)$ as:

$$
u(x)=\ln x, \quad v(c)=\zeta \ln c, \quad \gamma(W)=B+g \exp (-b W),
$$

where $\zeta>0$ and $b>0$. The steady-state point can be shown to be saddle-point stable if the following two conditions are met:

$$
1<\frac{r}{b \psi}<B
$$




$$
\psi\left(1+\frac{r B}{r-b \psi}\right)<(\alpha B-\psi) \zeta
$$

It is easy to find parameter sets that satisfy these conditions in a recursive way. The first inequality of (56) is met for a sufficiently large $r$, whereas the second inequality holds valid for a sufficiently large $B$. Given the $r$ and $B$ values, inequality (57) is met if we choose a sufficiently large $\alpha$ and a sufficiently large $\zeta$.

Next, consider a more general case in which $u$ and $v$ are of the CRRA type:

$$
u(x)=\left\{\begin{array}{cc}
\ln x & \text { if } \theta^{x}=1 \\
\frac{x^{1-1 / \theta^{x}}-1}{1-1 / \theta^{x}} & \text { otherwise }
\end{array}, v(c)=\left\{\begin{array}{cc}
\zeta \ln c & \text { if } \theta^{c}=1 \\
\zeta \frac{c^{1-1 / \theta^{c}}-1}{1-1 / \theta^{c}} & \text { otherwise }
\end{array},\right.\right.
$$

which reduces to the aforementioned logarithmic utility case when IESs equal one. As $u$ and $v$ are continuous at $\theta^{x}=1$ and $\theta^{c}=1$, respectively, conditions (56) and (57) are also sufficient for saddle-point stability in the CRRA case if $\left(\theta^{x}, \theta^{c}\right)$ is sufficiently near $(1,1)$. Note that, in the neighborhood of $\left(\theta^{x}, \theta^{c}\right)=(1,1)$, at which $\varepsilon=0$, the tempting good can be either a luxury $(\varepsilon>0)$ or an inferior $(\varepsilon<0){ }^{21}$

\section{Appendix 4: Good-specific time preferences}

- Derivation of Eq. (23)

By definition Eq. (22), time preference $\delta_{t}^{x}$ is given by

$$
\delta_{t}^{x}=r-\frac{M U_{x a}}{M U_{x}} \dot{a}_{t}-\frac{M U_{x W}}{M U_{x}} \dot{W}_{t}-\frac{M U_{x \lambda}}{M U_{x}} \dot{\lambda}_{t},
$$

where $M U_{x}$ is the RHS of Eq. (12). Substitute

$$
\dot{a}_{t}=\chi\left(a_{t}-a^{*}\right), \dot{W}_{t}=\chi\left(W_{t}-W^{*}\right), \dot{\lambda}_{t}=\chi\left(\lambda_{t}-\lambda^{*}\right)
$$

into the above. Eliminating $\lambda_{t}-\lambda^{*}$ by using the linearized version of Eq. (12) and substituting Eqs. (20) and (18) yields the expression of $\delta_{t}^{x}$ in Eq. (23). In the same way, we can derive $\delta_{t}^{c}$ in Eq. (23).

- Sufficient conditions for Eq. (24)

To discuss sufficient conditions for $\varepsilon>\varepsilon_{-}$, we start with the following property:

Lemma 1 If $u^{\prime \prime \prime}(x) \geq 0$, there is a lower bound for $\varepsilon$ around the steady state, such that

$$
\varepsilon \geq 1-\frac{\theta^{c} \theta^{T}}{\theta^{x}} \frac{x^{T}}{x}
$$

\footnotetext{
21 We can show numerical solutions that are saddle-point stable with parameters that do not satisfy sufficient conditions (56) and (57), e.g., $B=0$. Proof of the sufficient conditions and the numerical solutions are available upon request.
} 
Proof Parameter $\varepsilon$ can be re-expressed as

$$
\varepsilon=1-\frac{c u^{\prime}\left(x^{T}\right) \frac{\theta^{c}}{\theta^{x}}}{q x\left\{u^{\prime}(x)-u^{\prime}\left(x^{T}\right)\right\}}=1+\frac{u^{\prime}\left(x^{T}\right) \frac{\theta^{c}}{\theta^{x}}}{x \frac{\left\{u^{\prime}\left(x^{T}\right)-u^{\prime}(x)\right\}}{x^{T}-x}},
$$

where the last equality follows as $c / q=(r a+y-q x) / q=x^{T}-x$ around the steady state. Thus, if $u^{\prime \prime \prime}(x) \geq 0$ and hence $u^{\prime}(x)$ is weakly convex, we have $\frac{\left\{u^{\prime}\left(x^{T}\right)-u^{\prime}(x)\right\}}{x^{T}-x} \leq$ $u^{\prime \prime}\left(x^{T}\right)$, so that

$$
\varepsilon \geq 1+\frac{u^{\prime}\left(x^{T}\right) \frac{\theta^{c}}{\theta^{x}}}{x u^{\prime \prime}\left(x^{T}\right)}=1-\frac{\theta^{c} \theta^{T}}{\theta^{x}} \frac{x^{T}}{x} .
$$

With the lemma, we propose the following sufficient condition.

Sufficient condition 1: Inequality (24) holds valid if

$$
u^{\prime \prime \prime}(x) \geq 0 \text { and } \theta^{c}<\frac{\theta^{x}}{\theta^{T}} \frac{x}{x^{T}}+\left(\frac{1+\gamma(1+\alpha \lambda)}{(1+\alpha \lambda) \gamma}\right)\left(\frac{u^{\prime}(x)}{u^{\prime}\left(x^{T}\right)}\right)\left(\frac{r-\chi}{r}\right) .
$$

Proof Suppose that $u^{\prime \prime \prime}(x) \geq 0$. Then, from the definition of $\varepsilon_{-}$and the above lemma, we have $\varepsilon>\varepsilon_{-}$if

$$
1-\frac{\theta^{c} \theta^{T}}{\theta^{x}} \frac{x^{T}}{x}>-\left(\frac{x^{T}}{x}\right)\left(\frac{1+\gamma(1+\alpha \lambda)}{(1+\alpha \lambda) \gamma}\right)\left(\frac{u^{\prime}(x)}{u^{\prime}\left(x^{T}\right)}\right)\left(\frac{r-\chi}{r}\right)\left(\frac{\theta^{T}}{\theta^{x}}\right),
$$

which can be rearranged to the second inequality of sufficient condition 1 .

As $\left(\frac{1+\gamma(1+\alpha \lambda)}{(1+\alpha \lambda) \gamma}\right)\left(\frac{u^{\prime}(x)}{u^{\prime}\left(x^{T}\right)}\right)\left(\frac{r-\chi}{r}\right)$ is greater than one, the above condition is sufficiently met if $u^{\prime \prime \prime}(x) \geq 0$ and either of the following conditions are met:

1. $\theta^{c} \leq 1$;

2. $u$ is of the CRRA type (and, hence, $\theta^{x}=\theta^{T}$ ) and $\theta^{c} \leq 1+x / x^{T}$;

3. $u$ is of the CARA type (and, hence, $x \theta^{x}=x^{T} \theta^{T}$ ) and $\theta^{c} \leq 2$,

where condition 1 is the first item of Example 2 in Sect. 3.2.3.

Inequality $\varepsilon<\varepsilon_{+}$holds valid if $\theta^{T} \geq \theta^{x}$, because $\varepsilon \leq 1$ and $\varepsilon_{+}>\theta^{T} / \theta^{x}$, as referred to as the second item of the example shown in Sect.3.2.3.

\section{Appendix 5: The LWC and LST schedules}

Under the assumption that $\Phi<0$ in Appendix 3, we can show from Eqs. (21) and (33) that: 


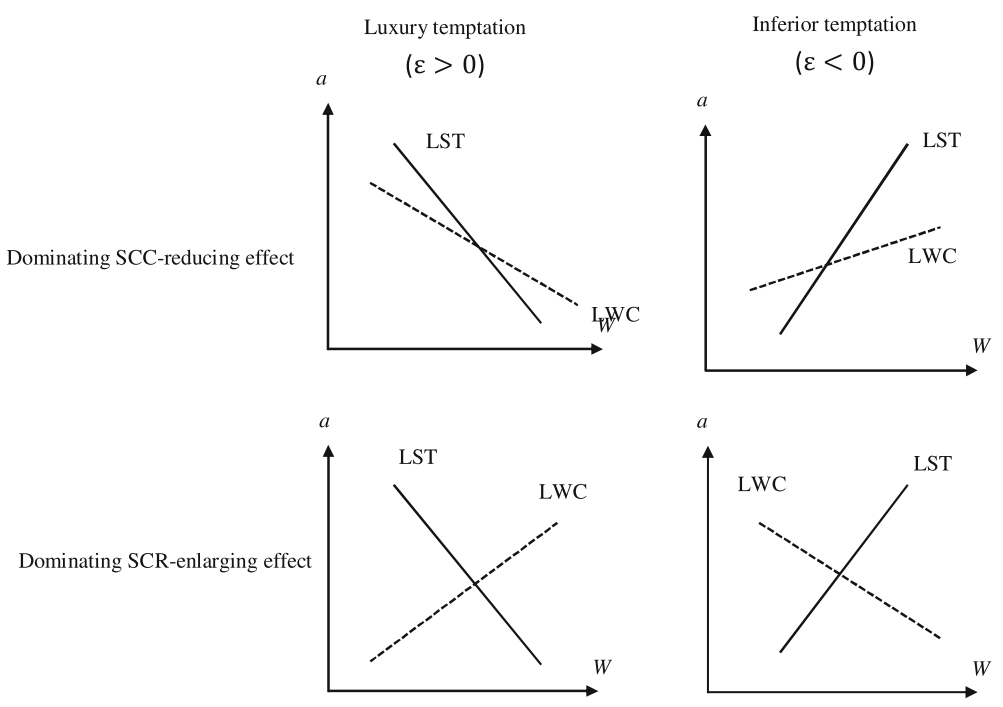

Fig. 3 Steady-state optimum solutions. Note The figure illustrates the determination of steady-state optimum solution for willpower $W^{*}$ and wealth hoding $a^{*}$. in the possible four cases defined by whether the tempting good is a luxury $(\varepsilon>0)$ or an inferior $(\varepsilon<0)$ and which of the self-control cost (SCC) reducing effect and selfcontrol requirement (SCR) enlarging effect is dominating (see Sect. 3.2.4 for the two effects)

- when $x$ is marginally a luxury $(\varepsilon>0)$,

$$
\left.\frac{d a}{d W}\right|_{L S T}<0,\left.\frac{d a}{d W}\right|_{L S T}<\left.\frac{d a}{d W}\right|_{L W C} ;
$$

- when $x$ is marginally an inferior $(\varepsilon<0)$,

$$
\left.\frac{d a}{d W}\right|_{L S T}>0,\left.\frac{d a}{d W}\right|_{L S T}>\left.\frac{d a}{d W}\right|_{L W C},
$$

meaning that the LST is negatively or positively sloping as $\varepsilon$ is positive or negative; and that the relative magnitudes of the slopes of the two schedules depend on the sign of $\varepsilon$. Note that when $\varepsilon>0$, the LWC has a negative or positive slope, as the negative SCC-reducing effect of self-control dominates or is dominated by the positive SCRenlarging effect, whereas the opposite is true when $\varepsilon<0$. It follows that we can illustrate the typical LWC and LST schedules in four ways, depending on whether $\varepsilon$ is positive or negative and whether the negative SCC-reducing effect dominates or is dominated by the positive SCR-enlarging effect, as shown in Fig. 3. 


\section{Appendix 6: The results of comparative statics}

- Initial wealth and willpower

$$
\begin{aligned}
\frac{d a^{*}}{d a_{0}} & =\frac{S C}{\kappa_{1}}, \\
\frac{d a^{*}}{d W_{0}} & =\frac{S C}{\kappa_{1}} \Omega, \\
\frac{d W^{*}}{d a_{0}} & =\frac{-\alpha r \gamma q\left\{u^{\prime}(x)-u^{\prime}\left(x^{T}\right)\right\}^{2}\left\{u^{\prime}(x)-u^{\prime}\left(x^{T}\right) \varepsilon\right\} v^{\prime \prime} \varepsilon}{\kappa_{1}}, \\
\frac{d W^{*}}{d W_{0}} & =\frac{-\alpha r \gamma q\left\{u^{\prime}(x)-u^{\prime}\left(x^{T}\right)\right\}^{2}\left\{u^{\prime}(x)-u^{\prime}\left(x^{T}\right) \varepsilon\right\} v^{\prime \prime} \varepsilon}{\kappa_{1}} \Omega>0, \\
\frac{d x}{d a_{0}} & =X_{W} \frac{d W^{*}}{d a_{0}}+X_{a} \frac{d a^{*}}{d a_{0}}, \\
\frac{d x}{d W_{0}} & =X_{W} \frac{d W^{*}}{d W_{0}}+X_{a} \frac{d a^{*}}{d W_{0}}, \\
\frac{d c}{d a_{0}} & =C_{W} \frac{d W^{*}}{d a_{0}}+C_{a} \frac{d a^{*}}{d a_{0}}, \\
\frac{d c}{d W_{0}} & =C_{W} \frac{d W^{*}}{d W_{0}}+C_{a} \frac{d a^{*}}{d W_{0}},
\end{aligned}
$$

where

$$
\begin{aligned}
S C= & -\alpha \gamma^{\prime}\left\{u\left(x^{T}\right)-u(x)\right\} q^{2}\left\{u^{\prime}(x)-u^{\prime}\left(x^{T}\right)\right\}^{2} v^{\prime \prime} \varepsilon^{2} \\
& +\frac{\{1+(1+\alpha \lambda) \gamma\} u^{\prime \prime}(x) u^{\prime}(x)^{2}}{r+\alpha \gamma^{\prime}\left\{u\left(x^{T}\right)-u(x)\right\}} \Phi \geq 0
\end{aligned}
$$

$\Leftrightarrow$ SCC-reducing effect $\leq$ SCR-enlarging effect,

$$
\begin{aligned}
& \kappa_{1}=\frac{\left[r+\alpha \gamma^{\prime}\left\{u\left(x^{T}\right)-u(x)\right\}\right] q^{2}\left\{u^{\prime}(x)-u^{\prime}\left(x^{T}\right)\right\}^{2} v^{\prime \prime} \chi \varepsilon^{2}}{r-\chi} \\
& +\frac{\{1+(1+\alpha \lambda) \gamma\} u^{\prime \prime}(x) u^{\prime}(x)^{2}}{r+\alpha \gamma^{\prime}\left\{u\left(x^{T}\right)-u(x)\right\}} \Phi>0, \\
& X_{W}=\frac{\left[-\gamma^{\prime}\left(r+\alpha \gamma^{\prime}\left(u\left(x^{T}\right)-u(x)\right)\right)+\alpha \gamma \gamma^{\prime \prime}\left(u\left(x^{T}\right)-u(x)\right)\right] u^{\prime}(x)(1+\alpha \lambda)^{2}}{r^{2}(1+(1+\alpha \lambda) \gamma) u^{\prime \prime}(x)+r \alpha \gamma \gamma^{\prime} u^{\prime}(x)^{2}(1+\alpha \lambda)^{2}+q^{2} r^{2} v^{\prime \prime}}<0, \\
& X_{a}=\frac{1}{r\left(1+\left(1+\alpha \lambda \gamma^{\prime} u^{\prime}\left(x^{T}\right) u^{\prime}(x)(1+\alpha \lambda)^{2}+q^{2} r v^{\prime \prime}\right\}\right.}>0, \\
& C_{W}=\frac{q\left[\gamma^{\prime}\left(r+\alpha \gamma^{\prime}\left(u\left(x^{T}\right)-u(x)\right)\right)-\alpha \gamma \gamma^{\prime \prime}\left(u\left(x^{\prime}(x)^{2}(1+\alpha \lambda)^{2}+q^{2} r v^{\prime \prime} \frac{1}{q}>0(x)\right)\right] u^{\prime}(x)(1+\alpha \lambda)^{2}\right.}{r^{2}(1+(1+\alpha \lambda) \gamma) u^{\prime \prime}(x)+r \alpha \gamma \gamma^{\prime} u^{\prime}(x)^{2}(1+\alpha \lambda)^{2}+q^{2} r^{2} v^{\prime \prime}}>0,
\end{aligned}
$$




$$
C_{a}=\frac{\alpha \gamma \gamma^{\prime} u^{\prime}(x)(1+\alpha \lambda)^{2}\left(u^{\prime}(x)-u^{\prime}\left(x^{T}\right)\right) r+r^{2}(1+(1+\alpha \lambda) \gamma) u^{\prime \prime}(x)}{r(1+(1+\alpha \lambda) \gamma) u^{\prime \prime}(x)+\alpha \gamma \gamma^{\prime} u^{\prime}(x)^{2}(1+\alpha \lambda)^{2}+q^{2} r v^{\prime \prime}(c)}>0 .
$$

- Willpower recovery rate

$$
\begin{aligned}
\frac{d W^{*}}{d \psi} & =\frac{\kappa_{2}\left[u^{\prime}(x)-u^{\prime}\left(x^{T}\right)\right]\left\{u^{\prime}(x)-u^{\prime}\left(x^{T}\right) \varepsilon\right\}}{\kappa_{1}}>0, \\
\frac{d a^{*}}{d \psi} & =\frac{-\kappa_{2}\left[u^{\prime}(x)-u^{\prime}\left(x^{T}\right)\right]\left\{u^{\prime}(x)-u^{\prime}\left(x^{T}\right) \varepsilon\right\}}{\kappa_{1}} \Omega, \\
\frac{d x^{*}}{d \psi} & =\left(X_{W}-X_{a} \Omega\right) \frac{\kappa_{2}\left[u^{\prime}(x)-u^{\prime}\left(x^{T}\right)\right]\left\{u^{\prime}(x)-u^{\prime}\left(x^{T}\right) \varepsilon\right\}}{\kappa_{1}}, \\
\frac{d c^{*}}{d \psi} & =\left(C_{W}-C_{a} \Omega\right) \frac{\kappa_{2}\left[u^{\prime}(x)-u^{\prime}\left(x^{T}\right)\right]\left\{u^{\prime}(x)-u^{\prime}\left(x^{T}\right) \varepsilon\right\}}{\kappa_{1}},
\end{aligned}
$$

where

$$
\kappa_{2}=-\frac{\alpha \gamma \gamma^{\prime} u^{\prime}(x)^{2}(1+\alpha \lambda)^{2}}{r}-(1+(1+\alpha \lambda) \gamma) u^{\prime \prime}(x)-q^{2} v^{\prime \prime}>0 .
$$

- Endowment income

$$
\begin{aligned}
\frac{d W^{*}}{d y} & =\frac{-\alpha r \gamma q\left\{u^{\prime}(x)-u^{\prime}\left(x^{T}\right)\right\}^{2}\left\{u^{\prime}(x)-u^{\prime}\left(x^{T}\right) \varepsilon\right\} v^{\prime \prime} \varepsilon}{r \kappa_{1}}, \\
\frac{d a^{*}}{d y} & =\frac{\alpha r \gamma q\left\{u^{\prime}(x)-u^{\prime}\left(x^{T}\right)\right\}^{2}\left\{u^{\prime}(x)-u^{\prime}\left(x^{T}\right) \varepsilon\right\} v^{\prime \prime} \varepsilon}{r \kappa_{1}} \Omega<0, \\
\frac{d x^{*}}{d y} & =\frac{-\alpha r \gamma q\left\{u^{\prime}(x)-u^{\prime}\left(x^{T}\right)\right\}^{2}\left\{u^{\prime}(x)-u^{\prime}\left(x^{T}\right) \varepsilon\right\} v^{\prime \prime} \varepsilon}{r \kappa_{1}} X_{W}+\frac{S C}{r \kappa_{1}} X_{a}, \\
\frac{d c^{*}}{d y} & =\frac{-\alpha r \gamma q\left\{u^{\prime}(x)-u^{\prime}\left(x^{T}\right)\right\}^{2}\left\{u^{\prime}(x)-u^{\prime}\left(x^{T}\right) \varepsilon\right\} v^{\prime \prime} \varepsilon}{r \kappa_{1}} C_{W}+\frac{S C}{r \kappa_{1}} C_{a} .
\end{aligned}
$$

\section{Appendix 7: The case with willpower-enhancing effects of self-control}

In the text, we have focused on the willpower-depleting effect of self-control in tempting good consumption. As is shown in psychological experiments (e.g., Muraven et al. 1999; Baumeister and Vohs 2016b), and as is casually believed, self-control toughens future willpower as if training strengthened one's muscle. In psychological theory, the model of toughenable willpower is called the muscle model (e.g., Baumeister and Vohs 2003). Here we incorporate the willpower-enhancing effect of self-control in the simplest way and thereby discuss on its implication. 
Specify the willpower-enhancing effect of self-control by assuming that the willpower recovery rate $\psi$ is an increasing and concave function of self-control costs $F: \psi(F), \psi^{\prime}>0, \psi^{\prime \prime}<0$, where

$$
F(x, W, a)=\gamma(W)\left\{u\left(x^{T}\right)-u(x)-u^{\prime}\left(x^{T}\right)\left(\frac{r a+y-q x-c}{q}\right)\right\} .
$$

The willpower flow constraint (8) is then changed to

$$
\dot{W}_{t}=\psi\left(F\left(x_{t}, W_{t}, a_{t}\right)\right)-\alpha F\left(x_{t}, W_{t}, a_{t}\right) .
$$

From Eq. (58), a marginal increase in self-control $F$ at time $t$ affects willpower at next instant $\dot{W}$ in two ways: it depletes the willpower by $\alpha$, and enhances the recovery rate by $\psi^{\prime}$. The net effect depends crucially on whether $\bar{\alpha} \equiv \alpha-\psi^{\prime}$ is positive or negative.

Formally, the local dynamic behavior under Eq. (58) is described by the system that is obtained by replacing $\alpha$ with $\bar{\alpha}$ in Eq. (54). Re-define $\Phi$ (Eq. (55)), $\chi$, and $\Omega$ (Eq. (21)) by using $\bar{\alpha}$, instead of $\alpha$, and denote them by $\bar{\Phi}, \bar{\chi}$, and $\bar{\Omega}$, respectively. In the same way as in Eq. (55), the necessary and sufficient condition for saddle-point stability is given by $\bar{\Phi}<0$. Suppose that the condition is met. Then, the optimal relations Eqs. (20) and (21) in the previous model are changed to, respectively,

$$
\begin{aligned}
x_{t}-x^{*} & =\frac{\left\{u^{\prime}(x)-u^{\prime}\left(x^{T}\right)\right\}\left[\bar{\chi} / \bar{\alpha}+\gamma^{\prime}\left\{u\left(x^{T}\right)-u(x)\right\}\right]}{\gamma\left[\left\{u^{\prime}(x)-u^{\prime}\left(x^{T}\right)\right\}^{2}+\frac{c}{q x} \frac{\theta^{c}}{\theta^{x}} u^{\prime}\left(x^{T}\right)^{2}\right]}\left(W_{t}-W^{*}\right), \\
a_{t}-a^{*} & =-\bar{\Omega}\left(W_{t}-W^{*}\right) .
\end{aligned}
$$

In these equations, note that the signs of the coefficients of $W_{t}-W^{*}$ depend crucially on the sign of $\bar{\chi} / \bar{\alpha}+\gamma^{\prime}\left(u\left(x^{T}\right)-u(x)\right)$. In particular, when the willpower-enhancing effect is strong enough that $\bar{\chi} / \bar{\alpha}+\gamma^{\prime}\left(u\left(x^{T}\right)-u(x)\right)$ is positive, the coefficients of $W_{t}-W^{*}$ have the opposite signs to those in Sect. 3, so that the optimal consumption of tempting good $x$ becomes smaller with weaker willpower $\left(d x_{t} / d W_{t}>0\right)$ : consumers with weaker willpower keep $x$ lower so as to toughen their future willpower.

\section{References}

Aguiar, M., Bils, M.: Has consumption inequality mirrored income inequality? Am. Econ. Rev. 105, 27272756 (2015)

Ahn, D.S., Iijima, R., Sarver, T.: Naiveté about temptation and self-control: foundations for naive quasihyperbolic discounting. J. Econ. Theory (2020). https://doi.org/10.1016/j.jet.2020.105087

Ashraf, N., Karlan, D., Yin, W.: Tying Odysseus to the mast: evidence from a commitment savings product in the Philippines. Q. J. Econ. 121, 635-672 (2006)

Attanasio, O.P., Pistaferri, L.: Consumption inequality. J. Econ. Perspect. 30, 3-28 (2016)

Banerjee, A.V., Duflo, E.: The economic lives of the poor. J. Econ. Perspect. 21, 141-167 (2007)

Baumeister, R.F., Vohs, K.D.: Willpower, choices, and self-control. In: Loewenstein, G., Read, D., Baumeister, R. (eds) Time and Decision. Russell Sage Foundation (2003)

Baumeister, R.F., Vohs, K.D.: Strength model of self-regulation as limited resource: assessment, controversies, update. Adv. Exp. Soc. Psychol. 54, 67-127 (2016) 
Baumeister, R.F., Vohs, K.D.: Misguided effort with elusive implications. Perspect. Psychol. Sci. 11, 574575 (2016)

Becker, G.S., Mulligan, C.B.: The endogenous determination of time preference. Q. J. Econ. 112, 729-758 (1997)

Blundell, R., Ray, R.: Testing for linear Engel curve and additively separable preferences using a new flexible demand system. Econ. J. 94, 800-811 (2084). https://doi.org/10.2307/2232296

Brody, G.H., Yu, T., Beach, S.R.H.: Resilience to adversity and the early origin of disease. Dev. Psychopathol. 28, 1347-1365 (2016)

Browning, M., Crossley, T.F.: Luxuries are easier to postpone: a proof. J. Polit. Econ. 108, 1022-1026 (2000)

Bucciol, A., Houser, D., Piovesan, M.: Willpower in children and adults: a survey of results and economic implications. Int. Rev. Econ. 57, 259-267 (2010)

Das, M.: Optimal growth with decreasing marginal impatience. J. Econ. Dyn. Control 27, 1881-1898 (2003)

de Lange, F.P., Koers, A., Kalkman, J.S., Bleijenberg, G., Hagoort, P., van der Meer, J.W.M., Toni, I.: Increase in prefrontal cortical volume following cognitive behavioural therapy in patients with chronic fatigue syndrome. Brain 131, 2172-2180 (2008)

Drugeon, J.-P., Wlgnlolle, B.: On impatience, temptation and Ramsey's conjecture. Econ. Theory 63, 73-98 (2017)

Epstein, L.G.: A simple dynamic general equilibrium model. J. Econ. Theory 41, 68-95 (1987)

Evans, D.R., Boggero, I.A., Segerstrom, S.C.: The nature of self-regulatory fatigue and "ego depletion": lessons from physical fatigue. Pers. Soc. Psychol. Rev. 20, 291-310 (2016)

Fields, S.A., Lange, K., Ramos, A., Thamotharan, S., Rassu, F.: The relationship between stress and delay discounting: a meta-analytic review. Behav. Pharmacol. 25, 434-444 (2014)

Fisher, I.: The Theory of Interest. Macmillan, London (1930)

Frederick, S.G., Loewenstein, G., O’Donoghue, T.: Time discounting and time preference: A critical review. J. Econ. Lit. 40, 351-401 (2002)

Fudenberg, D., Levine, D.K.: A dual self model of impulse control. Am. Econ. Rev. 96, 1449-1476 (2006)

Fudenberg, D., Levine, D.K.: Timing and self-control. Econometrica 80, 1-42 (2012)

Giavazzi, F., Wyplosz, C.: The zero root problem. Rev. Econ. Stud. 52, 353-357 (1985)

Kopylov, I., Noor, J.: Commitments and weak resolve. Econ. Theory 66, 1-19 (2018). https://doi.org/10. 1007/s00199-017-1061-0

Liang, M., Grant, S., Hsieh, S.: Costly self-control and limited willpower. Econ. Theory 70, 607-632 (2020). https://doi.org/10.1007/s00199-019-01231-6

Liu, L., Niu, Y., Wang, Y., Yang, J.: Optimal consumption with time-inconsistent preference. Econ. Theory 70, 785-815 (2020). https://doi.org/10.1007/s00199-019-01228-1

Gul, F., Pesendorfer, W.: Temptation and self-control. Econometrica 69, 1403-1435 (2001)

Gul, F., Pesendorfer, W.: Self-control and the theory of consumption. Econometrica 72, 119-158 (2004)

Hagger, M.S., Wood, C., Stiff, C., Chatzisarantis, N.L.D.: Ego depletion and the strength model of selfcontrol: a meta-analysis. Psychol. Bull. 136(4), 495-525 (2010)

Hagger, M.S., et al.: A multi-lab pre-registered replication of the ego-depletion effect. Perspect. Psychol. Sci. 11, 546-573 (2016)

Hanaoka, C., Shigeoka, H., Watanabe, Y.: Do risk preferences change? Evidence from the Great East Japan Earthquake. Am. Econ. J. Appl. Econ. 10, 298-330 (2018)

Heckman, J.J.: Skill formation and the economics of investing in disadvantaged children. Science 312, 1900-1902 (2006)

Hinson, J.M., Jameson, T.L., Whitney, P.: Impulsive decision making and working memory. J. Exp. Psychol. Learn. Mem. Cogn. 29, 298-306 (2003)

Hirose, K., Ikeda, S.: Decreasing and increasing marginal impatience and the terms of trade in an interdependent world economy. J. Econ. Dyn. Control 36, 1551-1565 (2012)

Hori, T., Futagami, K.: A non-unitary discount rate model. Economica 86, 139-165 (2019)

Ikeda, S.: Luxury and wealth. Int. Econ. Rev. (Philadelphia) 47, 495-526 (2006)

Inzlicht, M., Schmeichel, B.J.: What is ego depletion? Toward a mechanistic revision of the resource model of self-control. Perspect. Psychol. Sci. 7, 450-463 (2012)

Inzlicht, M., Schmeichel, B.J., Macrae, C.N.: Why self-control seems (but may not be) limited. Trends Cogn. Sci. 18, 127-133 (2014)

Job, V., Dweck, C.S., Walton, G.M.: Ego depletion—is it all in your head? Implicit theories about willpower affect self-regulation. Psychol. Sci. 20, 1-8 (2010) 
Job, V., Walton, G.M., Berneckerm, K., Dweck, C.S.: Implicit theories about willpower predict selfregulation and grades in everyday life. J. Pers. Soc. Psychol. 108, 637-647 (2015)

Jones, B.F.: The human capital stock: a generalized approach. Am. Econ. Rev. 104, 3752-3777 (2014)

Kelley, W.M., Wagner, D.D., Heatherton, T.F.: In search of a human self-regulation system. Annu. Rev. Neurosci. 38, 389-411 (2015)

Kivetz, R., Keinan, A.: Repenting hyperopia: an analysis of self-control regrets. J. Consum. Res. 33, 273-282 (2006)

Krusell, P., Kuruşçu, B., Smith, A.A.: Equilibrium welfare and government policy with quasi-geometric discounting. J. Econ. Theory 105, 42-72 (2002)

Kurzban, R., Duckworth, A., Kable, J.W., Myers, J.: An opportunity cost model of subjective effort and task performance. Behav. Brain. Sci. 36, 661-726 (2013)

Lawrance, E.C.: Poverty and the rate of time preference: evidence from panel data. J. Polit. Econ. 99, 54-77 (1991)

Lempert, K.L., Porcelli, A.J., Delgado, M.R., Tricomi, E.: Individual differences in delay discounting under acute stress: the role of trait perceived stress. Front. Psychol. 3, 1-10 (2012)

Loewenstein, G.: Willpower: a decision-theorist's perspective. Law. Philos. 19, 51-76 (2000)

Loewenstein, G., O'Donoghue, T., Bhatia, S.: Modeling the interplay between affect and deliberation. Decision 2, 55-81 (2015)

Masatlioglu, Y., Nakajima, D., Ozdenoren, E.: Willpower and compromise effect. Theor. Econ. 15, 279-317 (2020)

Miller, G.E., Yu, T.Y., Chen, E., Brody, G.H.: Self-control forecasts better psychosocial outcomes but faster epigenetic aging in low-SES youth. PNAS 112, 10325-10330 (2015)

Moffitt, T.E., et al.: A gradient of childhood self-control predicts health, wealth, and public safety. PNAS 108, 2693-2698 (2011)

Muraven, M., Tice, D.M., Baumeister, P.F.: Self-control as limited resource: regulatory depletion patterns. J. Pers. Soc. Psychol. 74, 774-789 (1998)

Muraven, M., Baumeister, P.F., Tice, D.M.: Longitudinal improvement of self-regulation through practice: building self-control strength through repeated exercise. J. Soc. Psychol. 139, 446-457 (1999)

Noor, J.: Commitment and self-control. J. Econ. Theory 135, 1-34 (2007)

Noor, J., Takeoka, N.: Uphill self-control. Theor. Econ. 5, 127-158 (2010)

Obstfeld, M.: Intertemporal dependence, impatience, and dynamics. J. Monet. Econ. 26, 45-76 (1990)

O’Donoghue, T., Rabin, M.: Doing it now or later. Am. Econ. Rev. 89, 103-124 (1999)

Ohta, T., et al.: Effect of evacuation on body weight after the Great East Japan Earthquake. Am. J. Prev. Med. 50, 553-560 (2016)

Ojima, T.: General equilibrium dynamics with naive and sophisticated hyperbolic consumers in an overlapping generations economy. Economica 85, 281-304 (2018)

Okada, T., Tanaka, M., Kuratsune, H., Watanabe, Y., Sadato, N.: Mechanisms underlying fatigue: a voxelbased morphometric study of chronic fatigue syndrome. BMC Neurol. 4, 14 (2004)

Ozdenoren, E., Salant, S.W., Silverman, D.: Willpower and the optimal control of visceral urges. J. Eur. Econ. Assoc. 10, 342-368 (2012)

Posner, M.I., Rothbart, M.K.: Willpower and brain networks. ISSBD Bull. 2012(1), 7-11 (2012)

Reuben, E., Sapienza, P., Zingales, L.: Time discounting for primary and monetary rewards. Econ. Lett. 106, 125-127 (2010)

Shiv, B., Fedorikhin, A.: Heart and mind in conflict, The interplay of affect and cognition in consumer decision. J. Consum. Res. 26, 278-292 (1999)

Shoda, Y., Mischel, W., Peake, P.K.: Predicting adolescent cognitive and self-regulatory competencies from preschool delay of gratification: identifying diagnostic conditions. Dev. Psychol. 26, 978-986 (1990)

Sombart, W.: Liebe, Luxus und Kapitalismus (Munich: Dunckner \& Humblot), translated by W. R. Dittmar as: Luxury and Capitalism (Ann Arbor, MI: The University of Michigan Press, 1967) (1912)

Tanaka, M., Ishii, A., Watanabe, Y.: Regulatory mechanism of performance in chronic cognitive fatigue. Med. Hypotheses 82, 567-571 (2014)

Thaler, R.H., Shefrin, H.M.: An economic theory of self-control. J. Polit. Econ. 89, 392-406 (1981)

Tsukayama, E., Duckworth, A.: Domain-specific temporal discounting and temptation. Judgm. Decis. Mak. 5, 72-82 (2010)

Ubfal, D.: How general are time preferences? Eliciting good-specific discount rates. J. Dev. Econ. 118, $150-170(2016)$ 
Uzawa, H.: Time Preference, the consumption function and optimum asset holdings. In: J.N. Wolfe, ed. Value Capital and Growth: Papers in Honour of Sir John Hicks (Chicago: Aldine) (1968)

Vohs, K.D., Faber, R.J.: Spent resources: self-regulatory resource availability affects impulse buying. J. Consum. Res. 33, 537-547 (2007)

Vohs, K.D., Baumeister, R.F., Schmeichel, B.J.: Erratum to "Motivation, personal beliefs, and limited resources all contribute to self-control. J. Exp. Soc. Psychol. 49, 184-188 (2013)

Publisher's Note Springer Nature remains neutral with regard to jurisdictional claims in published maps and institutional affiliations.

\section{Affiliations}

\section{Shinsuke Ikeda ${ }^{1}$ (D) Takeshi Ojima ${ }^{2}$ (D)}

$凶 \quad$ Shinsuke Ikeda

ikeda@kwansei.ac.jp

Takeshi Ojima

t.ojima@econ.fukushima-u.ac.jp

1 Institute of Business and Accounting, Professional Graduate School, Kwansei Gakuin University, Nishinomiya, Hyogo 662-8501, Japan

2 Faculty of Economics and Business Administration, Fukushima University, Kanayagawa, Fukushima 960-1296, Japan 